\title{
EL CASTILLO BAJOMEDIEVAL: ARQUITECTURA Y TACTICA MILITAR
}

POR

ANTONIO NAVAREÑO MATEOS

LA abundancia de restos arquitectónicos de carácter castrense que aún se conservan en nuestra geografía, la mayor parte de ellos erigidos durante la Edad Media, ponen de manifiesto la dificultad que el hombre ha encontrado siempre para convivir pacíficamente y la cantidad de grandes y pequeños problemas que han presidido constantemente el desarrollo de la historia.

La época en la que se centra nuestra exposición fue especialmente densa en acontecimientos de esta índole, raramente resueltos por vía diplomática; se registran acciones de reconquista, enfrentamientos civiles, problemas de unidad nacional y conflictos internacionales, donde generalmente hubo que recurrir al uso de la fuerza.

Paralelamente a estos acontecimientos, se estaban fraguando múltiples cambios e innovaciones en todos los campos del conocimiento humano, desde lo filosófico a lo geográfico, desde lo religioso a lo humanístico, desde lo físico a lo artístico; lo que contribuye a que, sobre todo a finales de este período, en los siglos xiv y especialmente en el xv, afecten muy directamente al campo de la poliorcética, revolucionando con el uso de la pólvora las máquinas de guerra, la táctica militar y la arquitectura de fortificaciones. En estos siglos se simultanean métodos convencionales y modernos en la misma acción castrense; vemos construir castillos en pleno desarrollo de la artillería, donde junto a los taludes, troneras y baluartes que la arquitectura moderna exige seguirá levantándose el fácil blanco de su torre de homenaje. Es la fusión de lo antiguo y lo moderno, que quizá sea la característica predominante de esta época.

Por nuestra parte, nos centraremos sintéticamente en el desarrollo de la arquitectura militar dentro del área hispano-musulmana y en territorio cristiano, destacando los avances técnicos que se suceden en cada momento. Terminaremos con un comentario de lo que nos parece fue la táctica ofensiva frente a estas fortalezas y la consiguiente defensa de las mismas, basándonos en lo posible en las crónicas contemporáneas. 
Gladius, Vol. especial (1988), pp. 113-152 Actas del I Simposio Nacional

Cronológicamente nos situanos en las postrimerías del siglo xı, coincidiendo con la donación almohade sobre el territorio hispano-musulmán, por ser el momento en que se consolida un sistema defensivo de orden arquitectónico que se había venido gestando desde comienzos de la invasión sarracena en nuestro territorio.

Los almohades eran beréberes de las montaña del Atlas. En 1211 iniciaron un movimiento armado y religioso frente a los almorávides; tras dominar el Magreb, pasan a la Península, extendiéndose en el territorio inmediatamente. En 1157 dominaban todo el Al-Andalus, prolongándose su poderío hasta los primeros años del siglo xill. Aunque carecían de tradición cultural propia, supieron adaptarse a la civilización andaluza, asumiendo sus logros y adaptando éstos en beneficio propio, alcanzando el máximo desarrollo técnico y estratégico hasta entonces en las construcciones de carácter defensivo y militar del territorio.

Antes de adentrarnos en el análisis y características de sus construcciones militares, parece conveniente anotar de forma sucinta la génesis y evolución de las manifestaciones poliorcéticas musulmanas que les precedieron y que sin duda constituyeron su mejor antecedente e influencia.

En Oriente, el Califato omeya de Damasco desarrolla un tipo de fortificaciones, de ladrillo fundamentalmente, con trazado regular, cuadradas o rectangulares; con torres en los ángulos y torretas adosadas jalonando sus lienzos; puertas entre dos torres generalmente; inspirándose en la combinación de influencias mesopotámicas y helenísticas ${ }^{1}$.

Esta modalidad oriental se proyecta en la España musulmana con los Emiratos omeyas independientes de Damasco, y se consolida al fundirse con la tradición local, que había partido de similares orígenes, el sistema de fortificación romana, igualmente regular, con muros torreados, preferentemente de forma cuadrada, y puerta de acceso entre dos torres próximas, si bien en este caso su fábrica suele ser de sillería, características que se ponen de manifiesto en Coria (Cáceres) entre otros recintos fortificados construidos por los romanos ${ }^{2}$. La más antigua constlucción militar musulmana en España, la Conventual de Mérida, levantada a mediados del siglo IX, así lo atestigua, con su forma de cuadrado casi regular de unos 130 metros de lado, torres cuadradas macizas flanqueando los lienzos y barbacana defendiendo el puente y asegurando el suministro de

${ }^{1}$ Henri Terkasse, Les fortcresses de l'Espagne musulmane, Madrid, 1954, págs. $12-14$.

${ }^{2}$ Blas Tarracena, Arte romamo, en Ars Hispaniae, vol. II, Madrid, 1947, páginas 28.33. Cfr. Antonio Navareño Mateos, Arquilectura y urbamismo de Coria (Siglos XVI-XIX), Cáceres, 1982, págs. 59-88. 
agua, con su fábrica de sillares romanos reaprovechados, manifestando así la tradición romano-bizantina ${ }^{3}$. Se protege el acceso con un pequeño recinto fortificado - actualmente casi desaparecido- como ante-entrada ${ }^{4}$, que en alguna medida es el antecedente de los complicados y seguros accesos en recodo que desarrollaron los almohades.

En tiempos del Califato de Córdobo prevalece el aparejo de sillería, aunque desde finales del siglo $x$ y'a se generaliza el uso del hormigón $y$ argamasa durísima realizado por el sistema de encofrado, en este caso sobre base de piedra. El trazado sigue siendo regular, con torres rectangulares en ángulos y lienzos; la puerta igualmente entre dos torres, pero tendiendo ahora a prolongar el acceso en una especie de túnel o pasadizo interior. Se configuran ya unas características que a finales del siglo $\mathrm{x}$ sc marcan con nitidez y definen las bases de la futura arquitectura militar hispano-musulmana; $\mathrm{H}$. Terrasse ${ }^{5}$ destaca las siguientes: uso de sillería, mampostería o argamasa según recursos y necesidades, tendiendo cada vez más al empleo del último material; la ejecución de éste en encofrados obliga a la forma rectangular en evitación de la línea curva; tendencia a la geometría y simetría siempre que las condiciones topográficas del entorno lo permiten; prevalece una voluntad estética, de equilibrio y proporción siempre que ello sea compatible con su valor defensivo.

Como referencia podemos citar en este período los castillos de Tarifa, con aparejo a soga y tizón (960); Baños de la Encina, todo de argamasa, con torres cuadradas (967); Gormaz, con sillería irregular y puerı con axco de herradura; el recinto de Guadix, con torres de hormigón; el castillo de Trujillo, con grandes bloques sillares, puerta de herradura y dos largas corachas, aunque se discute su datación por la existencia de torres albarranas, que unos sitúan en el siglo x y otros en el xiI ${ }^{6}$ (Figs. 1-4).

Durante gran parte del siglo XI, con la disgregación del poder central

'Scgún inscripción allí encontrada, el edificio fue construido en el año 835 por' Abd-al-Rahmān II. Cfr. H. Terrasse, op. cit, pág. 15; Manuel Gómez Moreno, El arte arabe español hasta los almohades. Arte mozárabe, en Ars Hispaniae, volumen IIJ, Madrid, 1951, págs. 45-46.

4 Cer. Manuel Gómez Moreno, op. cil., págs. 45-46.

"H. Terrasse, op. cil., págs. 15-16.

"J. Lafuente y J. Zuznya, Algunas observaciones sobre el casillo de Trujillo, en Aclas del XXIII Congreso Internacional de Historia del Arte, 1973, Granada, 1976, págs. 119-127, donde datan el castillo a principios del siglo $x$ a más tardar, abriendo cl debate ante la contemplación de dos torres albarranas que creen contemporáneas del conjunto cuando no se conocen antecedentes de éstas antes del siglo Xil. Véanse Liopolvo Torres Balbás, Las torres albarranas, en Obra dispersa. I: Al-Andalus, crónica de la España musulmama, 2, Madrid, 1982, págs. 116-120; Basilio Pavón Maldonado, Arqueologia musulmana en C'áceres: aljibes medievales, en «Al-Andalus», vol. XXXII (Madrid, 1967), págs. 195-204, considerando la parts musulmana más antigua del siglo xı. 


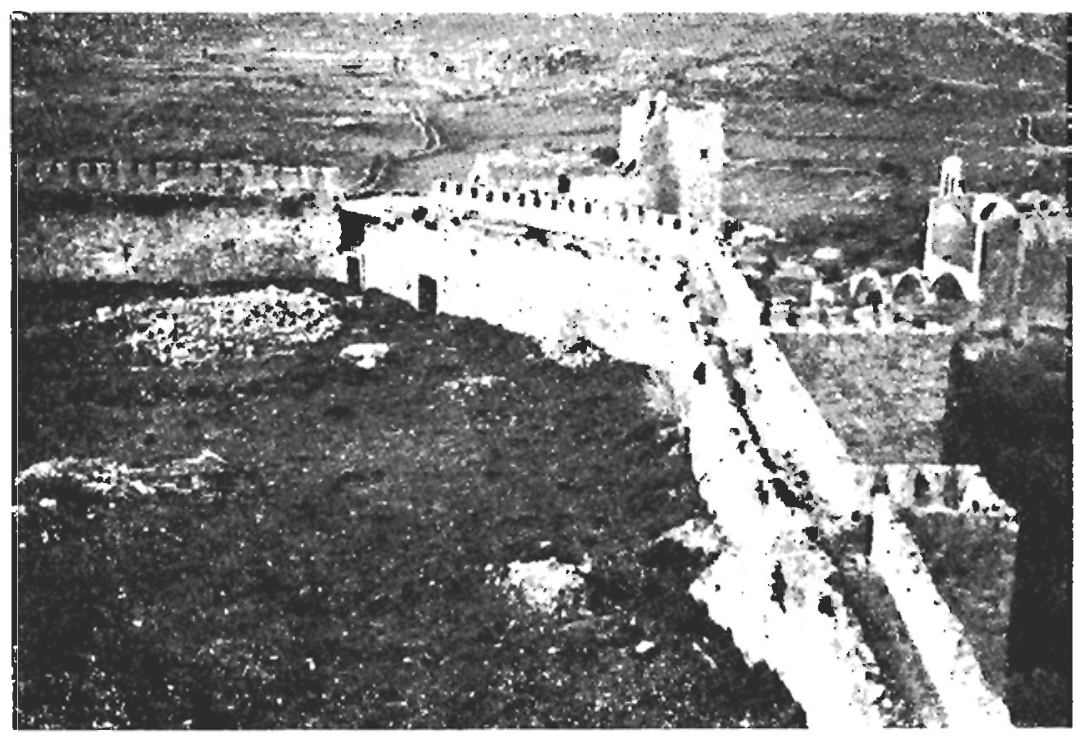

Fig. 1.-Epoca califal: Castillo de Trujillo (Cáceres). Corachas.

entre los distintos Tailas, desaparece la unidad anterior; como dice Terrasse, «la multiplicación de influencias y fronteras lleva a la multiplicación de las fortalezas» ${ }^{7}$. Se pierde la urandezal de la arquitectura califal en beneficio de una manifestación, como señala Martín González, «exclusivamente externa, de revestimiento, falsa»", que pretende aparentar superioridad respecto a los reinos locales vecinos, aunque en ningún caso deja de potenciarse lo estrictamente militar y defensivo. Entonces se levantan o refuerzan grandes recintos amurallados envolviendo a las más importantes ciudades: es la defensa de lo particular frente a la política anterior, de tipo territorial; así podemos destacar, entre otras:

- Alcazaba de Málaga. Para Torres Balbás es la obra militar más importante de las hispano-musulmanas persistentes en la actualidad, superando, incluso, a la Alhambra en acumulación de medios defensivos". Su

: H. Terrasse, op. cill, págs. 17-22.

Cfr. Juan José Martín Gonzílez, Hisloria de la arquilechura, Madrid, 1970. págs. 156-157.

Lropordo Torres Balbás, Excavaciones y obras en la alcazaba de Málaga (1934.1943), en Obra dispersa. I: Al-Andalus, crónica díc la España musulmana, 2, Makrid, 1982, paígs. 279-300. 
emplazamiento en lo alto de un cerro se constituye con dos recintos concéntricos con torres cuadradas y rectangulares macizas, de argamasa, con mampostería en algunas zonas; la entrada del recinto superior, más guarnecido, se efectúa entre dos torres, mientras que la principal del recinto exterior, llamada del Cristo, se dispone en recodo, peneirando tras el pri-

F1G. 2.-Epoca califal: Castillo de Trujillo (Cáceres). Corachas.

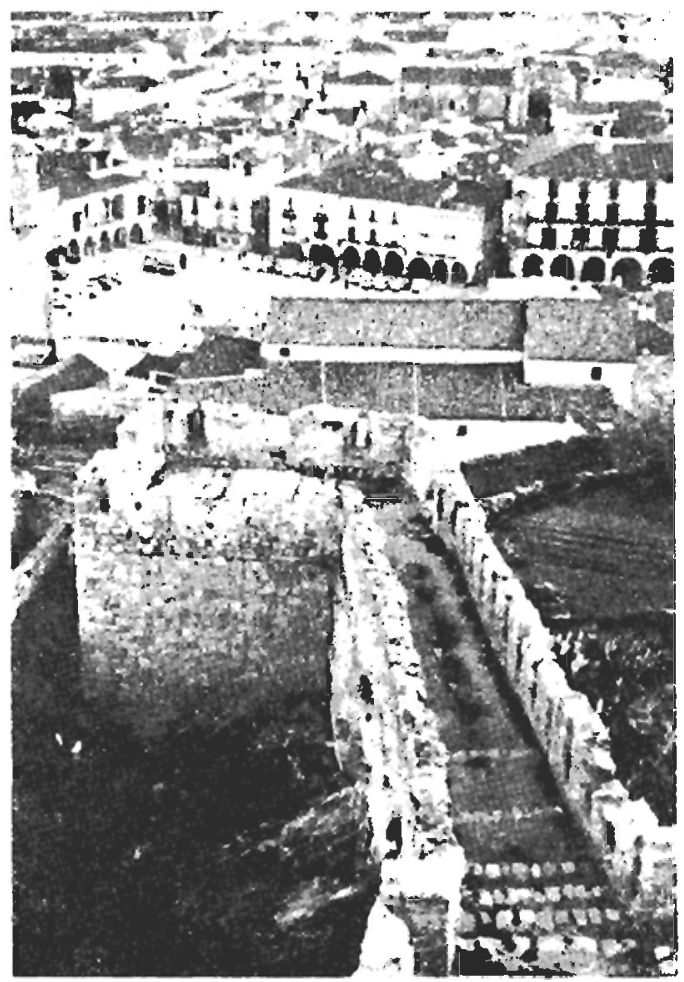

mer acceso a un recinto igualmente amurallado, a través del cual se continúa el ingreso por una segunda puerta con recodo y pasadizo ${ }^{19}$.

- Alcazaba Cadima de Granada, donde destaca su lienzo septentrional, restaurado a principios del siglo $\mathrm{xI}$, con torres macizas adosadas, cuadradas y redondas (las últimas no se difunden), todo de hormigón. La llamada puerta Monaita está protegida en el exterior por una barbacana

"Cfr. Manule Gómez Moreno, op. cit. 
e interiormente por un sistema de doble puerta entre las que se halla un patio de seguridad".

- Alcazaba de Almería. Sus muros de argamasa se adaptan a la topografía del terreno, dado lo irregular del emplazamiento; jalonan su reco-

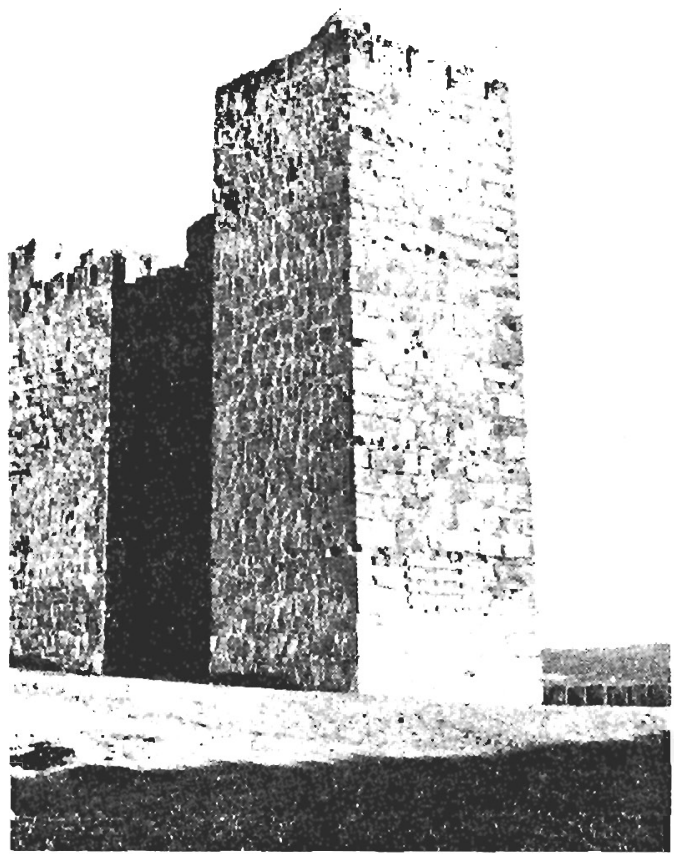

FIG. 3.-Epoce califal: Castillo de Trujillo (Cáceres). Torres.

rrido torres cuadradas, que superan la altura de la muralla, huecas en su parte superior, aunque sin bóveda.

- Los almorávides continúan con idéntica tradición constructiva; así, el «cascilleịo» de Monteagudo (Murcia), como siempre en to alto de un pronunciado cerro, rodeado de una segunda cerca torreada ${ }^{12}$. Auncue en este caso aparece la puerta de acceso entre dos torres macizas, los almo-

"I bid., págs. 255-256.
"I Ibid., pains 280-281. 


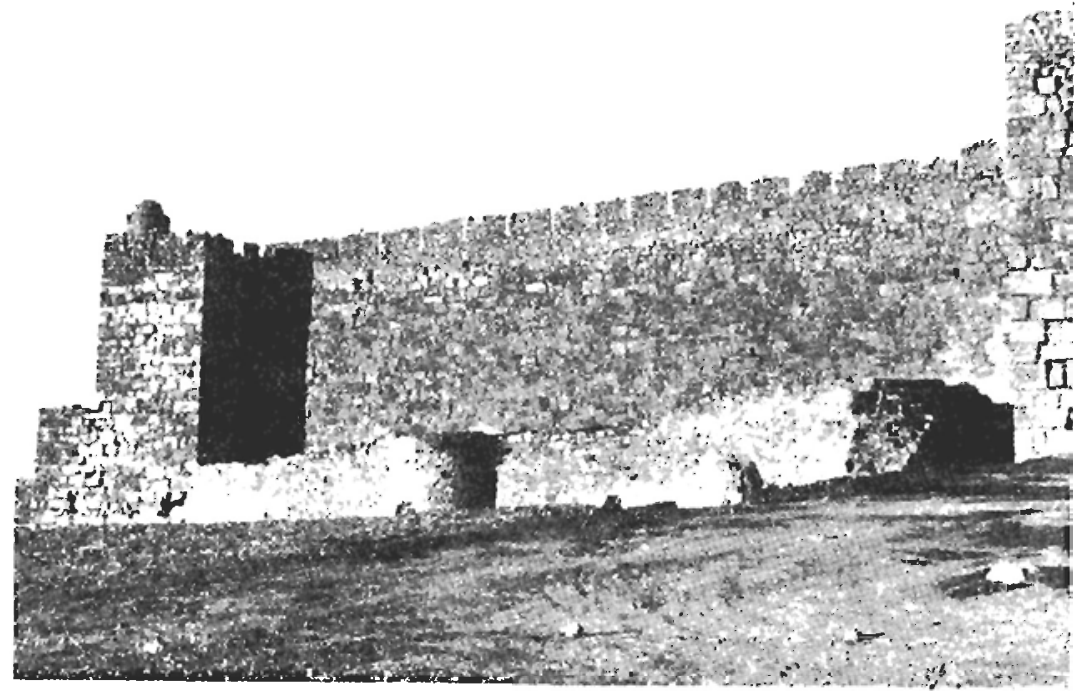

FIG. 4. -Epoca califal: Castillo de Truïllo (Cáceres). Lienzos.

rávides practican la entrada en recodo en el lateral de un torreón algo menos saliente que las almohades ${ }^{13}$.

Hasta aquí hemos pretendido reflejar esquemáticamente la evolución de las fortalezas musulmanas que, a lo largo de cuatro siglos, y partiendo de intecedentes orientales, bizantinos y romanos, habían generado un estilo propio que, sin apartarse demasiado de sus orígenes, habían sabido adaptarse a sus propias necesidades y recursos, mejorando notableriente las condiciones defensivas de aquéllas. Era, pues, la herencia que recibían los almubades en este campo; su cometido consistió en aunar selectivamente los mejores y más eficaces recursos utilizados por sus antecesores, lo que les permitirá levantar unas construcciones amuralladas útiles hastâ la aparición de las armas de fuego, y que serán protagonistas de los distintos enfrentamientos entre cristianos y musulmanes en los siglos siguientes.

Estas fortalezas o recintos amurallados se adaptan a lás condiciones topográficas del terreno con más exactitud que las anteriores ${ }^{14}$; consi-

13 Leoroldo Torres Balbás, Arle almorávide y almobade, CSIC, Madrid, 1955, págss. 21-22.

if H. 'Terrisse, op. cill, págs. 14-25. 
guiendo, en provecho propio, mejor rentabilidad táctica de los escarpes del terreno, se abandona nítidamente el rigor geométrico de la arquitectura califal. Perpetúan la antigua influencia bizantina en sus recintos dobles y barbacanas en los puntos de más difícil defensa y ante las puertas ${ }^{15}$, así como adosando a los muros las características torres cuadradas o rectangulares, mejorando su defensa con torres albarranas de igual formato o poligonales en algunos casos —octogonales las dos de Cáceres, tres en Ecija y una en Badajoz; dodecagonal y monumental la del Oro de Sevilla-. Se asume definitivamente y se generaliza la puerta de acceso en el flanco de una torre, trazando uno o varios recodos, con fachada de sillería o mampostería. Se emplea preferentemente la argamasa de almendrilla, mampuesto y trozos de ladrillo, unas veces sobre base de piedra tallada, que, en algunos casos, como el de Cáceres, son los restos de la primitiva muralla romana.

Con todo, como dice Terrasse ${ }^{16}$, se da lugar a una arquitectura militar pujante y de original belleza.

Podemos señalar distintos exponentes almohades que así lo manifiestan, algunos en Extremadura:

- Alcazaba de Badajoz, datada entre 1163-1184 ${ }^{17}$, se levanta en un elevado cerro junto al río Guadiana, ocupando un área aproximada de $200 \times 400$ metros. En su fábrica se combinan mampostería, cajones de tapial de argamasa y sillería en las puertas. Su perímetro se ve jalonado por torres rectangulares adosadas y otras albarranas, una de ellas, llamada de Espantaperros, retirada unos 25 metros del recinto y unida a él por un lienzo cuyo andén pone en comunicación aquuél y la cámara del primer piso de la torre. Según Torres Balbás ${ }^{18}$, paños de muralla unirían los frentes salientes de las albarranas, dando lugar a una barbacana a unos tres metros del muro principal.

Desde los dos ángulos del flanco septentrional partían sendas barreras o corachas, que se prolongan hasta el río, aislando la zona inmediata $y$ garantizando el suministro de agua y la defensa de la zona.

Las dos puertas que se conservan se abren entre sendas torres y el

is Terrasse (op. cit.) anota la posible influencia de las forrificaciones cristianas en este sentido.

16 Haid., pág. 26.

17 Cfr. Leopoldo Torres Bulnís, La alcazaba almobade de Badajoz, en Obra dispersa. I: Al-Andalus, crónica de la España musulmana, 1, Madrid, 1981, págs. 236275; también en Ars Hispaniae, vol. IV, Madrid, 1949, págs. 34-37; José MenéndezPidal Alvarez, La alcazaba musulmana de Badajoz (V Congreso de Estudios Extremeños), Badajoz, 1976; Manuei. Terrón Albarrín, El solar de los aftásidas, Matrid. 1971, págs. 629-642.

ik LeOpoldo Torres Balbís, op. cit. 
flanco de la muralla; tras el primer paso, se accede a un pequeño patio interior (de 8,85 × 6,10 metros: el de la puerta del «Capitel», y 6,40 $\times$ 4,70 metros: el de la puerta del «Apendiz»), dominado para su defensa desde los adarves de la muralla y torre; en la del Apendiz, la puerta se complica más, continuando su acceso por un pasadizo de casi 5 metros de largo.

- Cerca de Cáceres. Recinto algo más pequeño que el anterior (de $385 \times 187$ metros), levantado sobre base romana, de la que aún persisten varias hiladas de sillares en algunas torres y una de sus puertas. Torres Balbás la considera contemporánea de la de Badajoz o ligeramente posterior, de finales del siglo XII o comienzos del Xir ${ }^{19}$.

Su fábrica es de tapial de argamasa con sillares en esquinas de algunas torres; flanquean sus muros torres más altas que el adarve, de planta recrangular y otras cuadradas albarranas y dos oclogonales, cuyos lienzos de unión parten de los ángulos meridionales del recinto, del que le separan unos 12 metros. Estas eran macizas en su primer cuerpo y habitables en el segundo, bien conservado aún el de la llamada «Redonda» y desaparecido en la «Desmochada» (Figs. 5-6).

Como en el caso de Badajoz, parece que el saliente de estas torres albarranas estaría unido originariamente por una barrera exterior a modo de barbacana ${ }^{2)}$.

- Torre del Oro de Sevilla. Posiblemente fue torre albarrana unida al recinto por una muralla como avanzada o coracha para la defensa del puerto; tiene planta poligonal de doce lados y su fábrica es de sillería y argamasa; su interior está ocupado por tres pisos ${ }^{21}$; se data alrededor de 1220 .

Podemos recoger, en resumen, las características más importantes de los distintos elementos defensivos hasta aquí configurados:

De la primitiva puerta entre dos torres se ha pasado al acceso en recodo, generalizado en época almohade, lo que mejora las condiciones de seguridad y defensa al dificultar la entrada del posible agresor. Ya encontramos antecedentes en la puerta del Cristo de la Alca\%aba de Málaga y en la Monaita de la Alcazaba Cadima de Granada, ambas del siglo XI, y aún más tarde se proyectará en distintas construcciones cristianas, como veremos. Se logra así un sistema de doble puerta: tras flanquear la primera el posible atacante, se encontraría enfilado en el pequeño patio que

${ }^{14}$ Cfr. Leopoldo Torres Balbás, Cáceres y su cerca almohade, en Obra dispersa. I: Al-Andalus, crónica de la España musulmana, 4, Madrid, 1982, págs. 123-155; también en Ars Hispaniae, vol. IV, Madrid, 1949, págs. 32.34.

is Ibid.

" Leoroldo Torres Balbás, La Torre del Oro de Sevilla, en Obra dispersa. I: Al-Andalus, crónica de la España mustulmana, 1, Madrid, 1981, págs. 31-36. 


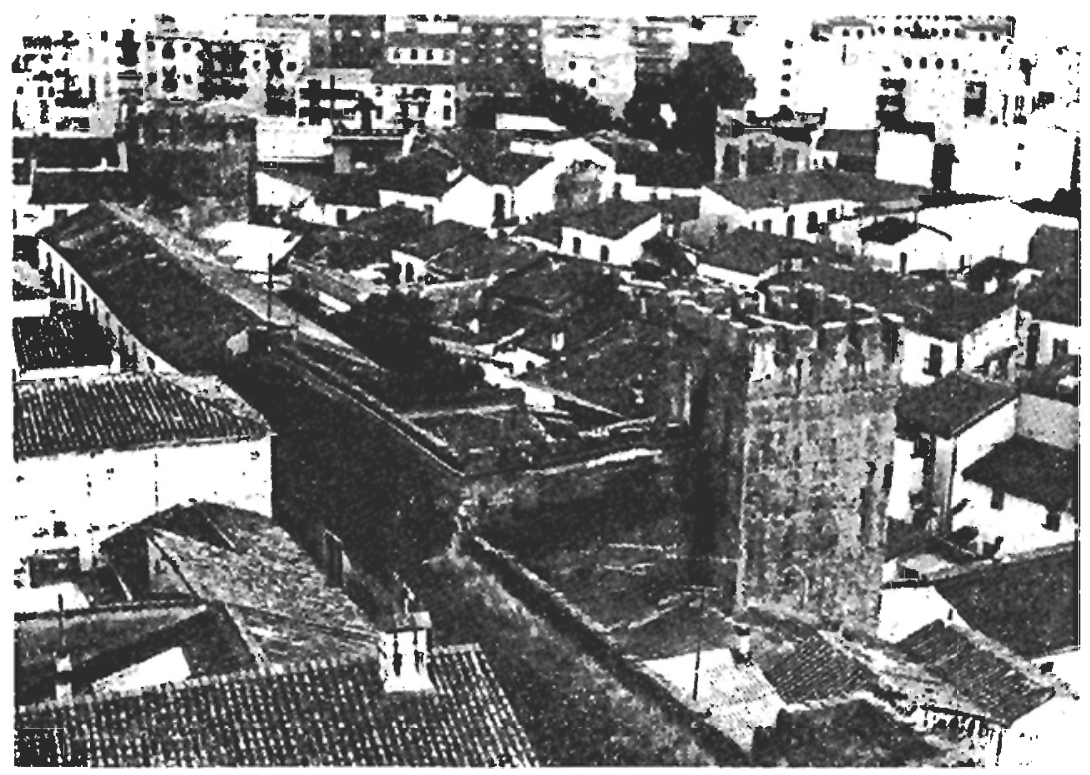

Fia. 5.-Fontificación almobade: Cerca de Cáceres. Lienzos y tories albarrenas.

precede a la segunda, mientras los defensores, en las rorres y adarves colindantes en el interior del recinto, permanecían en completo abrigo.

El empleo de argamasa y tapial facilita la rápicla y más económica construcción; el uso de encofrado en su fabricación se adapta a la cualidad moldeable del material, compatible con su solidez y dureza una vez fraguado. En cualquier caso, ello limita las formas de sus torres, que con esta técnica tienc que evitar las líneas curvas, por lo que prevalecen las torres cuadradas, de menor poder ofensivo que las cilíndricas, adoptando en ocasiones la sección octogonal o dodecagonal mmo aproximación al círculo. Ciertamente, esta fórmula no es original, existen antecedentes en la arquitectura romana y bizantina - puerta romana de «Córdoba» en Carmona--, pero ahora se desarrolla y difunde.

EI rigor geométrico se ve sustituido por la más exacta adaptación al eerreno, como la topografía impone, adaptación que se utiliza en beneficio propio, al aprovechar las defensas naturales que el terreno permite.

El empleo de coracbas, cuyas primeras manilestaciones ya veíamos en Mérida y Trujillo, permite la mejor defensa del terreno circundante, el 
suministro de agua en ocasiones, la defensa de un punto estratégico o la simple avanzadilla y punto de mira de una posible desenfilada en la ondulación del terreno, función que parecen desempeñar algunas torres albarranas (Figs. 1-4).

El poder defensivo de las torres adosadas ya era conocido y aplicado con anterioridad a la existencia del mundo musulmán; como hemos visto, con los almohades se incrementa el poder estratégico de éstas, haciéndolas albarranas, más salientes, con un pasillo bajo el andén que las une al adarve principal, lo que hace aumentar el ángulo y seguridad de tiro ante el enemigo que se acerca a la muralla y posibilita la erección de un segundo recinto inmediato al primero; se trata de cercar al posible asaltante (figuras 5-6).

Hasta ayuí hemos visto cómo estas fortificaciones estaban perfectamente adaptadas para oponerse a los medios ofensivos del momento, dificultando considerablemente el acceso directo y obligando al uso a distancia de distintos tipos de ingenios y máquinas de tiro, entonces de reducido poder destructor. Ahora el medio obligado será la zapa, la acción

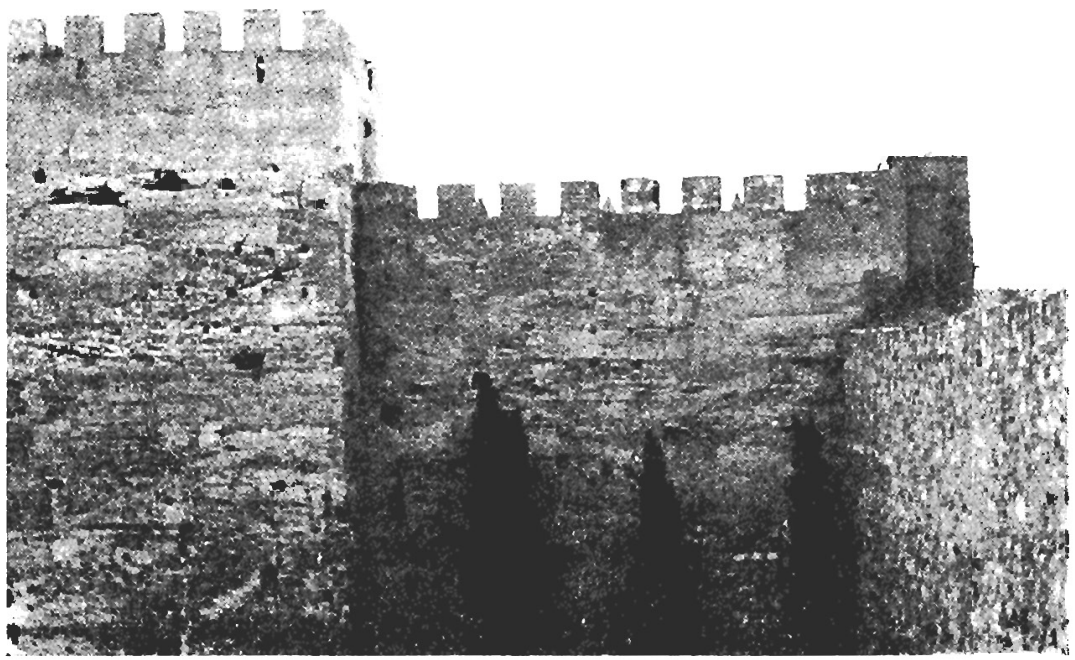

Fici. 6,-Forlificación almohade: Cerca de Cáceres, Torre albarrana del «Horno». 
Gladius, Vol. especial (1988), pp. 113-152

por sorpresa y sobre todo el ascdio, para lo cual también se dotan estas furtalezas de los aljibes necesarios. De todo ello daremos información más adelante.

No nos ocuparemos aquí del estudio de las construcciones nazaries, objeto de una ponencia en este simposio, tan sólo anotar el impacto que habría de suponer a mediados de este período la aparición de la artillería. Las construcciones que se levantan desde la segunda mitad del siglo XIII manifiestan !a tradición almohade con pocas innovaciones: las puertas se abren en recodo, varios en ocasiones, si bien se desarrollan más en profundidad; se continúa empleando torres albarranas, algunas de éstas o de las interiores, de mayores proporciones; las fortalezas son circundadas ahora por varios recintos amurallados, que, junto a la adopción de torres redondas en ocasiones, y por el empleo de mampostería y sillería en su fábrica hacen pensar a $\mathrm{H}$. Terrasse en una evidente influencia cristiana manifiesta en la frontera occidental del reino nazarí ${ }^{22}$. Pero es desde mediados del siglo xIV y en el xv, coincidiendo con la aparición y desarrollo de las armas de fuego, cuando se experimenta en la arquitectura militar un cambio notable, independiente del efecto destructivo real en los primeros tiempos de la artillería; ello obliga a la remodelación de algunas fortalezas ya existentes, reforzando no pocas veces sus muros y torres de tapial como si de un forro de piedra se tratara o construyendo baluartes adelantados, de menor altura, protegiendo las puertas y accesos. Las construcciones que ahora se levantan tratan de protegerse del efecto de los más potentes proyectiles y se acondicionan, al mismo ticmpo, para que en sus recintos puedan ser emplazadas estas innovadoras armas con parecidos métodos a los que se utilizaron en las fortalezas cristianas, como veremos en seguida.

En cualquier caso, aún en plena revolución armamentística, parece no abandonarse definitivamente los tradicionales sistemas defensivos, muchos de ellos naturales, considerando en primer lugar el mismo cmplazamiento del recinto o de la ciudad. Así parece confirmarlo Ibn Jaldun en la segunda mitad del siglo xiv: «Para que la vida de la ciudad sea grata es necesario atender, al fundarla, a varias condiciones: existencia de un río en su solar o fuente de agua pura abundante; lugar de aire puro; buenos pastos en los contornos y tierras de labor propias, montes o bosques; la ciudad debe construirse en la cumbre de una montaña abrupta, en una península o a orillas de un río franqueable tan sólo por un puente de barcas o de piedras; todas las cosas quedarán protegidas dentro de un cerco amurallado. Así la ciudad podrá defenderse sin la ayu-

\footnotetext{
$\because$ H. Terrasse, op. cit., págs. 32-33.
} 
Gladius, Vol. especial (1988), pp. 113-152

da del ejército» ${ }^{23}$. Veremos cómo estos principios dejarán de ser válidos desde el siglo xv, a juzgar por las sólidas construcciones que entonces se levantan y por la envergadura de las acciones bélicas que en ese tiempo se acometen.

\section{TERRITORIO CRISTIANO}

Durantc los años de reconquista, especialmente en las zonas fronterizas, la alternancia reiterada de moros y cristianos en el dominio de un mismo emplazamiento contribuyó a la configuración de un tipo de forti-

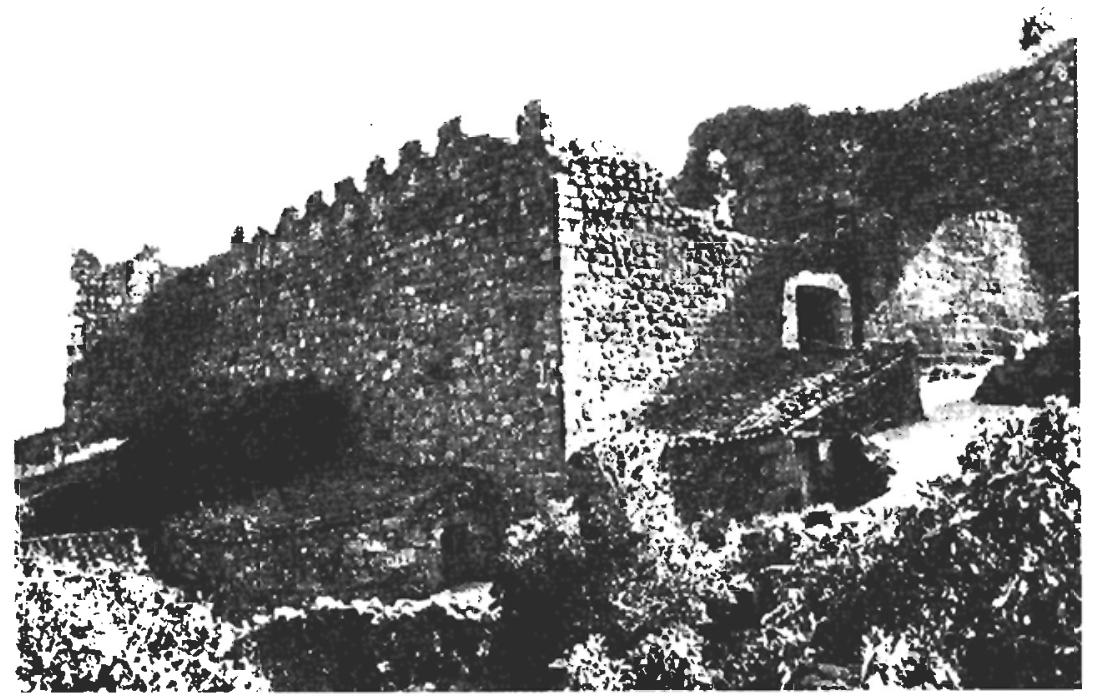

Fic. 7.--Emplazamiento fronterizo de reconquista: Castillo de Samibánez el Alto (Cáccres).

ficación un tanto ecléctica en cuanto a su tipología, combinándose elementos consiructivos musulmanes y cristianos. Son castillos auténticamente de vanguardia, enclavados en elevados e inaccesibles emplazamien-

". Leopoldo Torres Balbis, Ciudade's bispano-musulmanas, t. I, s. I., s. f, cilando a Ibn Jaldun. 


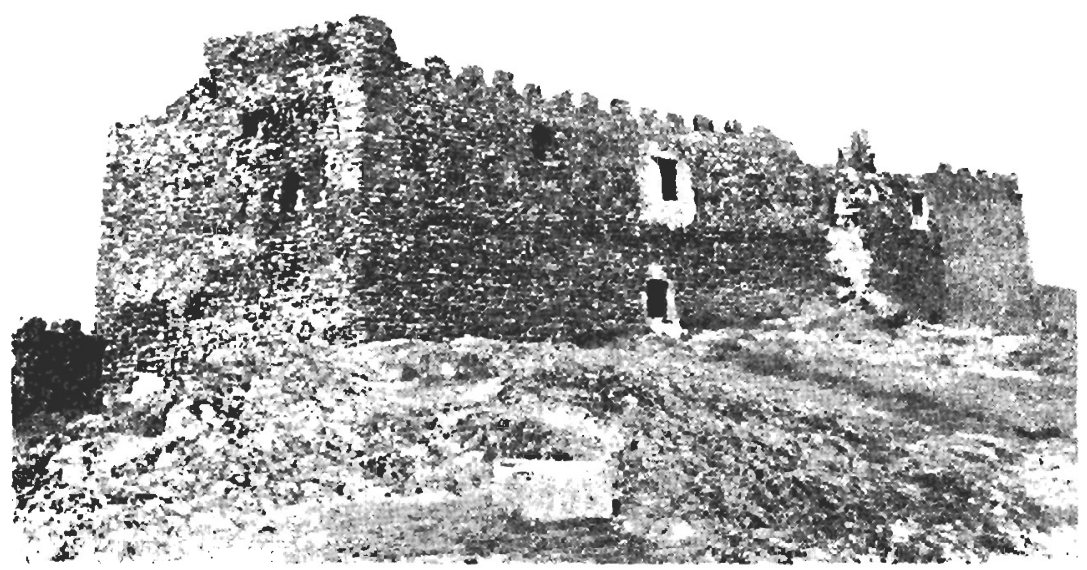

FIG. 8.-Emplazamiento fronterizo de reconquista: Castillo de Monlánchez (Cáceres).

tos, en las proximidades de un río o junto a vías de comunicación; en suma, en lugares de gran importancia estratégica.

Puede ser ejemplo de estas manifestaciones, desde la segunda mitad del siglo XII hasta mediados del siglo XIII, la frontera occidental del río Tajo, en la Alta Extremadura, donde en distintas líneas defensivas se registra gran acumulación de construcciones que funden lo musulmán y lo cristiano, prevaleciendo las características arquitectónicas de los últimos por las sucesivas reformas que éstos introdujeron, incluso con posterioridad a la fecha de su dominación definitiva. Así, las fortificaciones de Eljas, Santibánez el Alto y Almenara, en la Sierra de Gata, o las de Portezuelo, Alconétar y Montragïe, junto al río Tajo, o si se quiere, aún más al sur, el castillo de Montánchez, en la sierra del mismo nombre ${ }^{24}$ (figuras 7-10).

Estos emplazamientos, tras la reconquista, dieron lugar a villas fuertes, potenciadas generalmente por los monarcas como centros para la repoblación, concediendo fueros y privilegios o siendo entregaclas a las

${ }^{24}$ Cfr. Grinasio Velo Nieto, Castillos de Extremadura, Madrid, 1968. 
Ordenes militares o integrándose en distintos señoríos nobiliarios, como anteriormente ocurriera en el norte de la Penínsulá ${ }^{25}$.

A estas defensas se añade la muralla de la ciudad de Plasencia, mandada edificar por Alfonso VIII, durante el último cuarto del siglo XII, para consolidar el dominio de la Transierra. En este caso se destaca por el empleo de soluciones auténticamente cristianas, así su fábrica de sillería

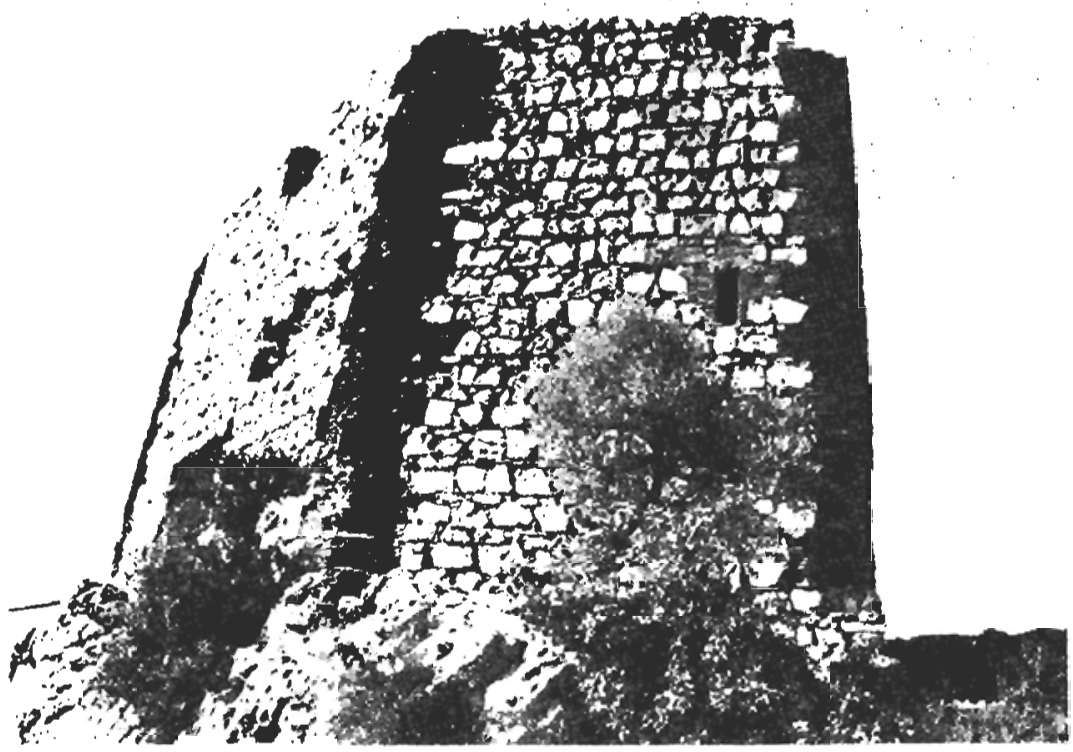

FIG. 9.-Emplazamicnto Jronterizo de reconquista C'astillo de Monlruyḯ (Cáceres).

y mampostería, con mortero de tierra y cal, y las torres semicilíndricas flanqueantes, que superan la altura de los adarves, como las de Avila.

Estos emplazamientos, junto a otros recintos amurallados, fueron hasta el siglo XIV el centro de la repoblación de las respectivas zonas, como indican los muros envolventes del caserío, quic desde entonces se levantarían en su entorno, lo mismo cjue se había manifestado con anterioridad en la frontera del Duero ${ }^{26}$.

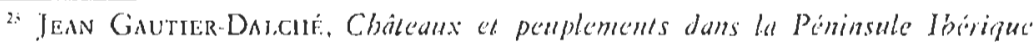
(Siecles X-XIII) (Premiìres Iomnées Internationales d'Histoire, 1979), cn «lilaran». I (Auch, 1980), pág. 103.

$\therefore$ Ihid., pig. 104. 


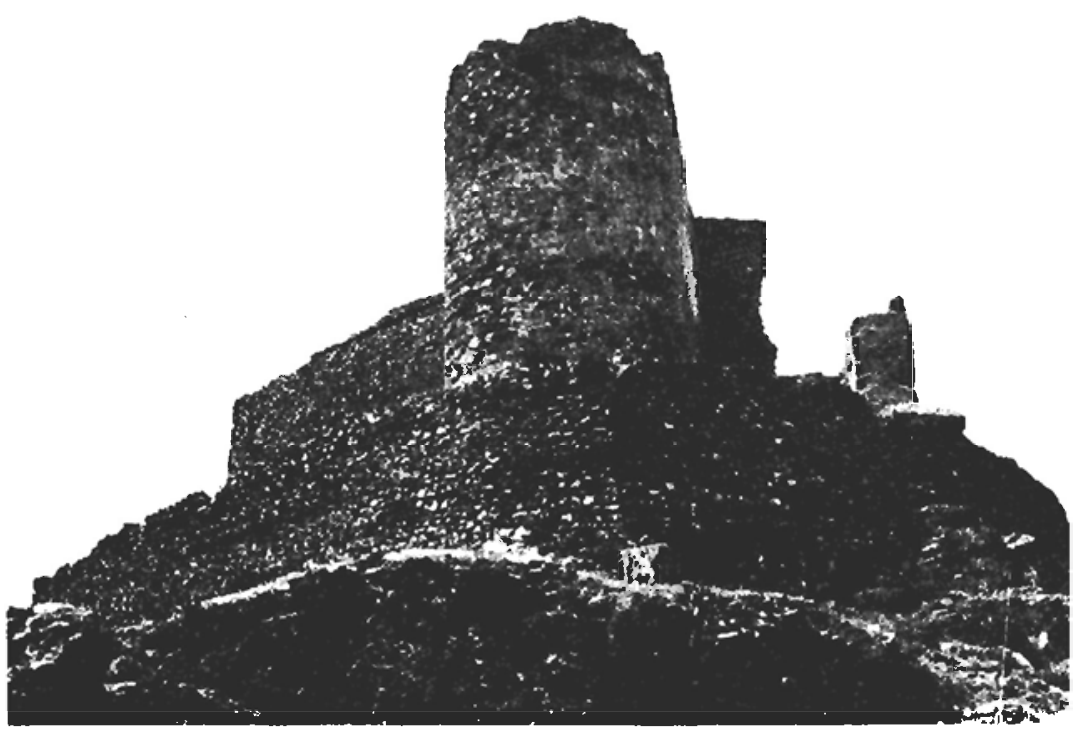

FIG. 10.-Emplazamiento fronlerizo de reconquista: Castillo de Portezuelo (Cáceres).

Desde el siglo XIV, en la medida que el peligro musulmán se aleja y se reduce al sur, en las zonas dominadas por los monarcas cristianos no disminuye el afán constructivo, si bien ahora ya no se trata de castillos de emergencia, de imprescindible necesidad militar; en su mayor parte son de tipo señorial y vienen a garantizar el dominio del rey ante la nobleza o de estas familias nobles entre sí, o ante el mismo rey en ocasiones ${ }^{27}$. Son castillos familiares, de dominio jurisdiccional civil, o de las Ordenes militares, levantados o reformados por éstas. En cualquier caso, estas fortificaciones ven incrementarse sus defensas, desarrollándose simultáneamente su complejo residencial: se funde lo defensivo y lo domésticoresidencial ${ }^{28}$ (Figs. 11-12).

Las plantas de estos castillos responden a distintas tipologías ${ }^{2 y}$ : se adopta la planta irregular según la imposición del propio terreno, ya que,

${ }^{27}$ Leopoldo Torres Balbís, Arquitectura gólica, en Ars Hispaniae, vol. VII, Madrid, 1952, págs, 253-257.

2* Vicente Lampírez y Romen, Arquitectura civil española, t. I, Madrid, 1922. píg. 229.

n) I hid., págs. 227.240 . 
en principio, se recurría a emplazamientos en lugares de difícil acceso; más tarde, cuando ya el peligro invasor parece definitivamente alejado, estos emplazamientos se realizan en lugares llanos y a veces explanados artificialmente, lo que permice su mayor regularidad y su forma generalmente cuadrada o rectangular; en ocasiones con tipología mixta: irregular su parte militar, la cerca; regular y geométrica su parte civil, lo residencial.

Su fábrica es de sillería o de mampostería. Las puertas suelen ser más pequeñas, normalmente con acceso directo, y en el mejor de los casos

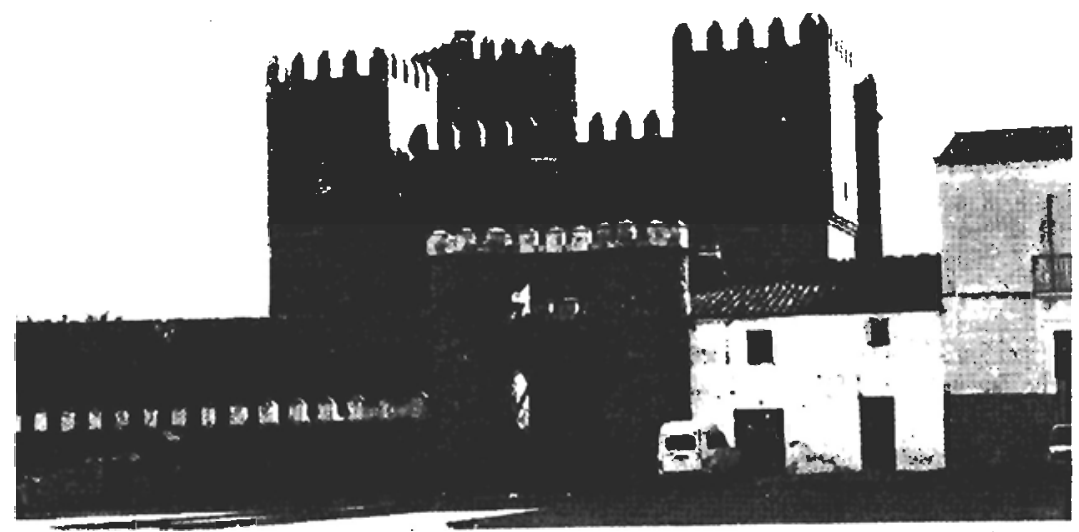

FIG. 11.-Castillo señertal de repoblación: Castillo de Monroy' (Cáceres).

pretendiendo imitar las de recodo musulmanas, con entrada entre dos muros paralelos, como en el castillo de «Mayoralgo», en las proximiditdes de Cáceres, o la «Puerta de la Viila», en la muralla de Galisteo, entı'c otras; suelen ir provistas de doble puerta, de hoja al exterior y con rastrillo o peine en el interior; en general, protegidas por torres flanqueantes y sobre todo por matacanes desde este siglo xiv, que más tarde se extenderá a lo largo de todo el coronamiento del muro, y que tiene su antecedente en las buhederas, a modo de elemental matacón ${ }^{29}$, como $\mathrm{cm}$

bil Cir. Leopoldo Torres Balbás, Arquitectura gótica, cil., págs. 253.257. 


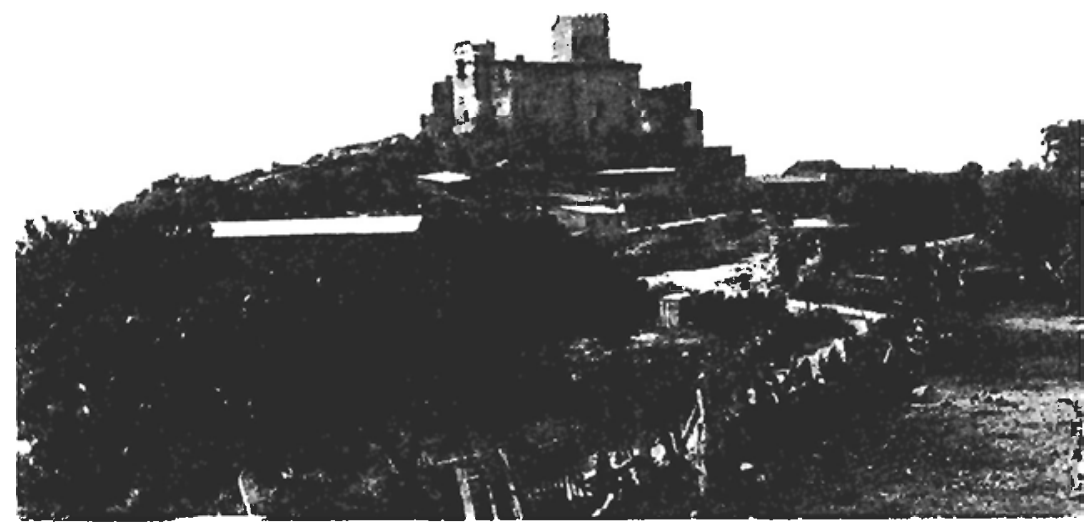

Frg. 12. Castillo señorial de repoblación: Castillo de Belvis de Monroy (Cáceres).

la «Puerta de Santa María», en Galisteo, que se dispone entre dos arcos en diferentes planos. Los lienzos se jalonan por torres o cubos adosados, semicilíndricos, que se generalizan desde fecha temprana, como atestiguan las murallas de Avila y Plasencia, con más salientes que las musulmanas, de quienes parecen tomar la modalidad albarrana. En torres y muros se abren saeteras y aspilleras con derrame interior, apareciendo éstas en torres y adarves, tanto en antepechos como en los mismos merlones. Todo era protegido por uno o varios recintos o cercas fortificadas, irregulares en terreno accidentado, disponiéndose en este caso a diferentes alturas, aprovechando, en propio beneficio, las defensas naturales del entorno. En el interior se destaca el patio de armas tras franquear la puerta principal; en su derredor se abren diversas dependencias de uso doméstico o de guarnición militar. Desde el siglo xrv, al mismo tiempo que se potencian las defensas, se desarrolla notablemente la parte residencial y se funde lo defensivo y lo civil ${ }^{31}$. En uno de los lados del patio, o en el centro a veces, se levanta la torre del bomenaje, situada en tal disposición que, aun dentro del recinto, pudiera ser fácilmente defendida en el supuesto que

"Cifr. Vicente Lampérez y Romes, op. cil., t. I, pág. 229. 
el conjunto fuera tomado por el adversario, como si de otra fortaleza se tratara; se aumentan sus defensas con matacanes y saeteras ${ }^{32}$; la torre de homenaje aglutina los valores simbólicos de tipo feudal y militar, por ser el lugar más inaccesible, ubicándose en su interior los aposentamientos, pertrechos y riquezas de sus titulares, complicándose su estructura aún más en el siglo siguiente, como veremos.

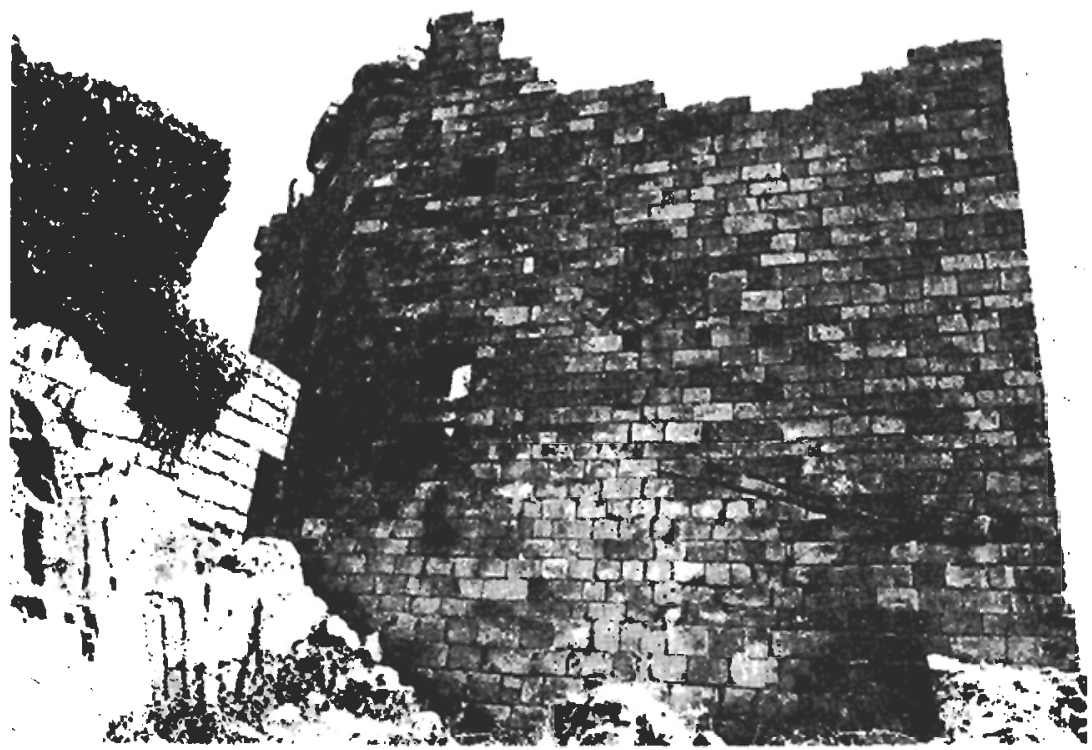

FIG. 13.-Castillo señorial del siglo XV: 'Trevejo (Cáceres).

En el siglo $X V$ se intensifica la presencia de los elementos arquitectónicos del siglo precedente, se añaden otros para atender a las nuevas necesidades militares que se imponen, aumentando los castillos en monumentalidad y en potencial defensivo, aunque, como señala Chueca, «no son, pues, castillos nacionales, baluartes de una lucha colectiva contra el invasor, sino castillos privados, erigidos por las familias poderosas» ${ }^{33}$. Ahora prevalece la planta generalmente rectangular, precediendo a su

32 lbíd., t. 11, pág. 398.

" Fernando Chueca Gomia, Historia de la arquilectura española, Madrid, 1965, píg. 662 . 


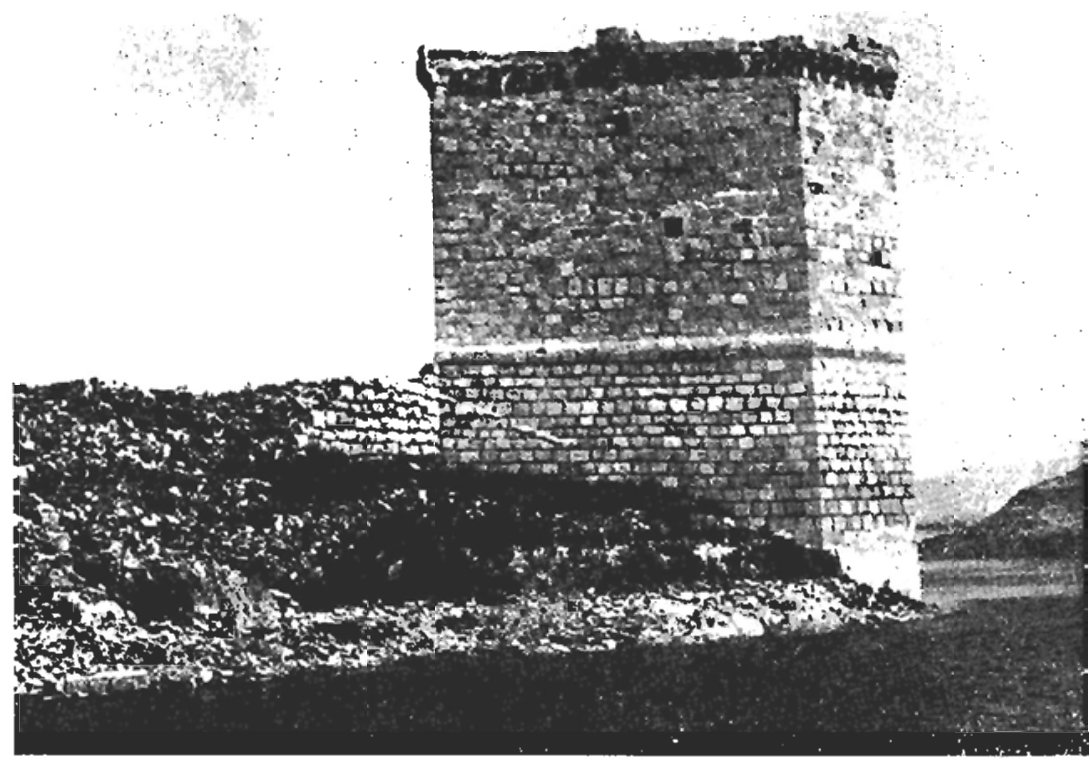

Frg. 14.-Castillo señorial del siglo XV: Alconétar (Cáceres).

cerca perimetral un foso en ocasiones. Se configuran distintos volúmenes, crecientes de fuera adentro: la barbacana exterior, el recinto o castillo propiamente dicho, a mayor altura, y en su interior, en el centro o a un lado del patio de armas, la torre del homenaje, manifestando con su estilizado diseño el linaje de sus propietarios. Generalmente, todos los lienzos, inclusive los de la torre del homenaje, se jalonan de torres semicilíndricas, al mismo tiempo que se extienden a lo largo de todo el adarve los matucanes corridos sobre canecillos, dando lugar a veces a galerías cubiertas, profusamente decoradas, como en el castillo de Manzanares el Real (Madrid), que hace recordar más lo palaciego que lo militar ${ }^{34}$. Descle 1454 , como señala Cooper ${ }^{35}$, aparecen en el centro de Castilla, y pronto se expanden, las garitas en los ángulos y flancos; se constituyen por ménsulas escalonadas, que posibilitan el voladizo del cuerpo cilíndrico, que asciende hasta ganar a veces en altura a los adarves, aunque se dis-

"Antonio Nuvareño Míteos, El casillo de las Arquijuelas de Abajo (Cáceres), en «Revista Norba», IV (Cáceres, 1983).

35 Envard) Cooper, Castillos señoriales de Castilla (Siglos XV y XVI), vol. I, págs. 26-30. 
Gladius, Vol. especial (1988), pp. 113-152 Actas del I Simposio Nacional

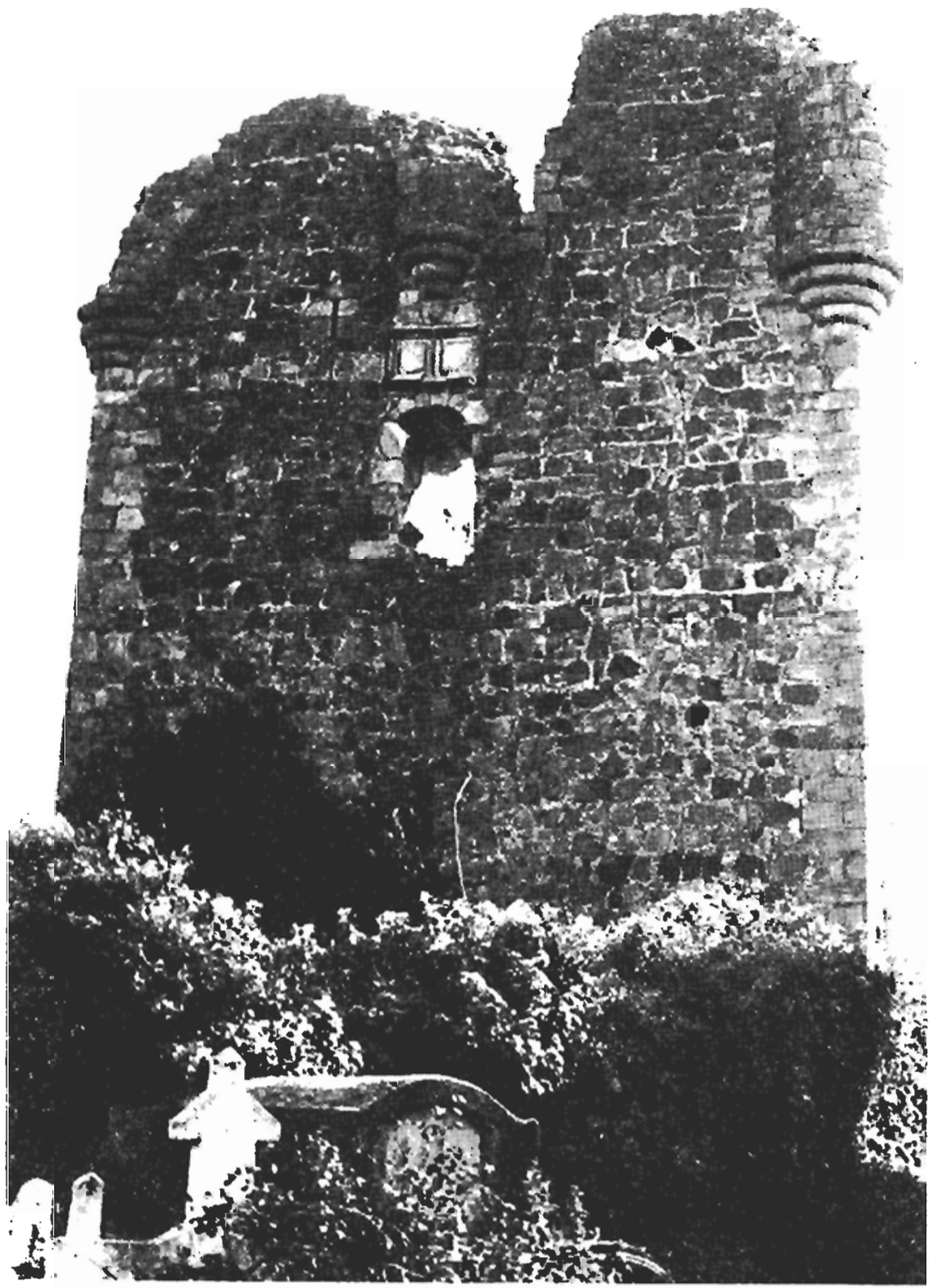

Fic;. 15.-Castillo señorial del siglo XV: Valverde de la Vera (Cáceres). 
Gladius, Vol. especial (1988), pp. 113-152 Actas del I Simposio Nacional

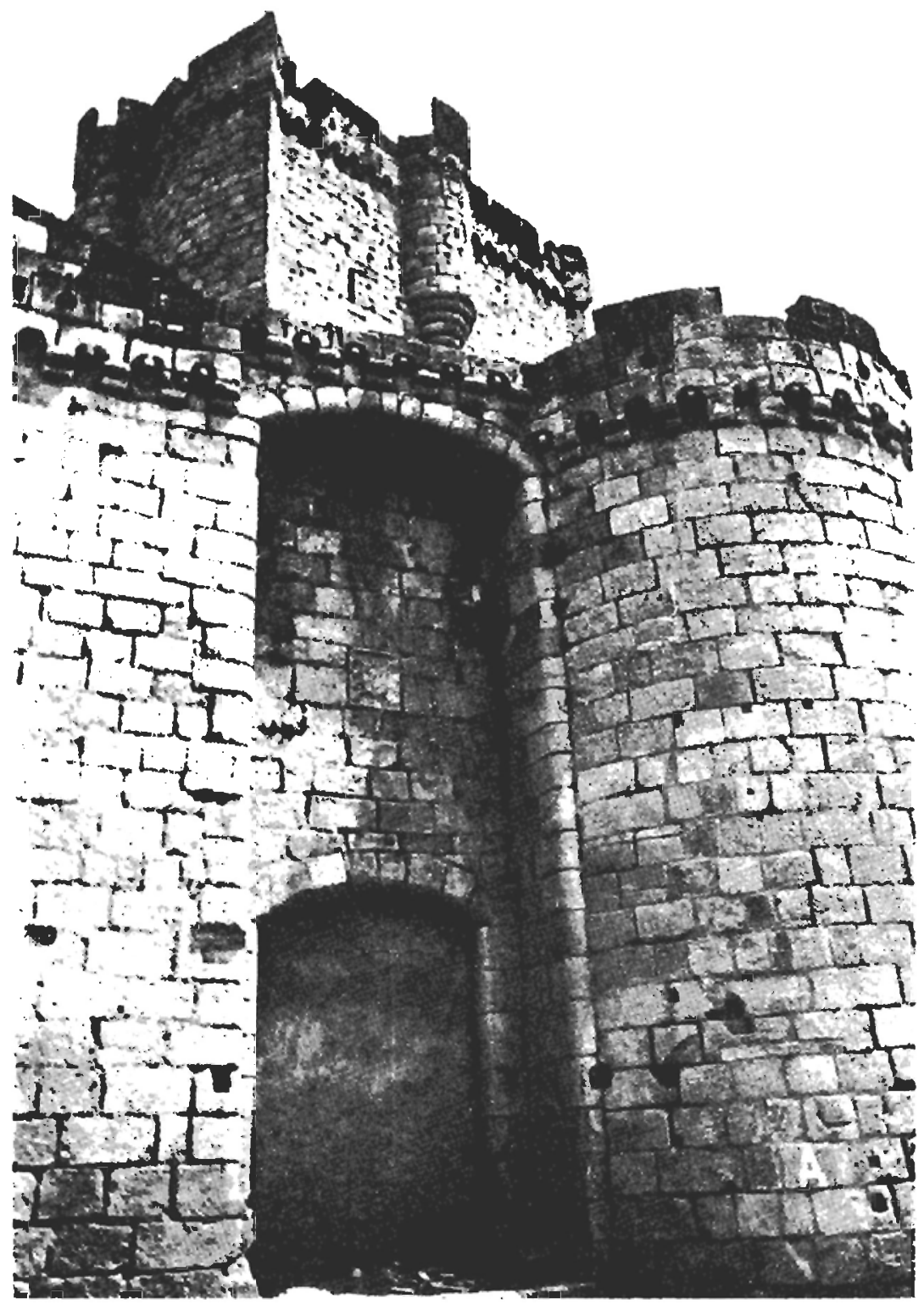

Fig. 16.-Castillo señorial del siglo XV: Coria (Cáceres). 
cute su poder ofensivo, dadas las zonas muertas que se crean en derredor de su base. Ahora la torre de bomenaje se monumentaliza, si bien se incrementan sus defensas y condiciones de seguridad; los accesos se efectúan desde el interior y desde el adarve; la comunicación entre las plantas altas se hace a través de escaleras móviles, lo que facilita su aislamiento ${ }^{36}$ (Figs. 13, 14, 15 y 16).

\section{Características defensivas que impone el uso de la artillería}

Mientras que en los reductos musulmanes parecen improvisarse los medios arquitectónicos que posibilitan la mejor defensa y uso de las nuevas armas de fuego, que desde el siglo xıv se imponen, quizá por la intensa presión reconquistadora, en los reinos cristianos la no urgencia permite una asimilación progresiva y ordenada de estos medios, a lo que también contribuyó la mayor influencia europea, especialmente italiana; así vemos cómo en este siglo Xv se levantan nuevos castillos o remodelan algunos de los anteriores, caracterizándose por la aparición, entre otros, de los siguientes elementos arquitectónicos, tanto defensivos como ofensivos:

Troneras. Se encuentra el primer caso en Zafra, en 1437, aunque no es hasta 1460 cuando se generaliza su uso ${ }^{37}$. Sus formatos son variados, constituyéndose por un orificio circular, donde se apoyaría la boca o caña del arma y una ranura vertical, crucífera o de otras formas, como posible punto de mira; su diámetro estaba en función del volumen de la pieza, según se tratara de uso individual o de tipo pesado; en la parte interior, embutida en el muro, se abría una oquedad abocinada con derrame interior, que permite el acoplamiento del arma y de su servidor. Más tarde aparece la de forma rectangular, con derrame exterior, como en el baluarte que se adosa en el castillo de Trujillo en $1470^{38}$. Los dispositivos para armas pesadas se disponen en la planta baja, para efectuar un tiro rasante, o en los adarvcs, en cuyo caso suelen ir montadas sobre casamatas o bóvedas muy sólidas, acampanadas, que aumentan la resistencia ante el peso y las vibraciones que habian de soportar.

La acción ofensiva acometida por estas nuevas piezas artilleras - lom-

${ }^{36}$ En el castillo de Montánchez, al menos en los últimos años del siglo xv, el acceso a la torre del homenaje se efectuaba desde el interior y desde el adarye; a la parte superior se ascendía por una «escalera de palo» desde la cámara contigua. Cfr. Antonio Nayareño Matreos, El castillo de Montánchez al linal de la Edad Media, en Actas del VII Congreso de Estudios Extremeños, tomo I, Cáceres, 1983, págs. 171-192.

${ }^{37}$ EDWhrd CoOper, op. cit., pág. 54.

3* Ibíd., pág. 55 . 

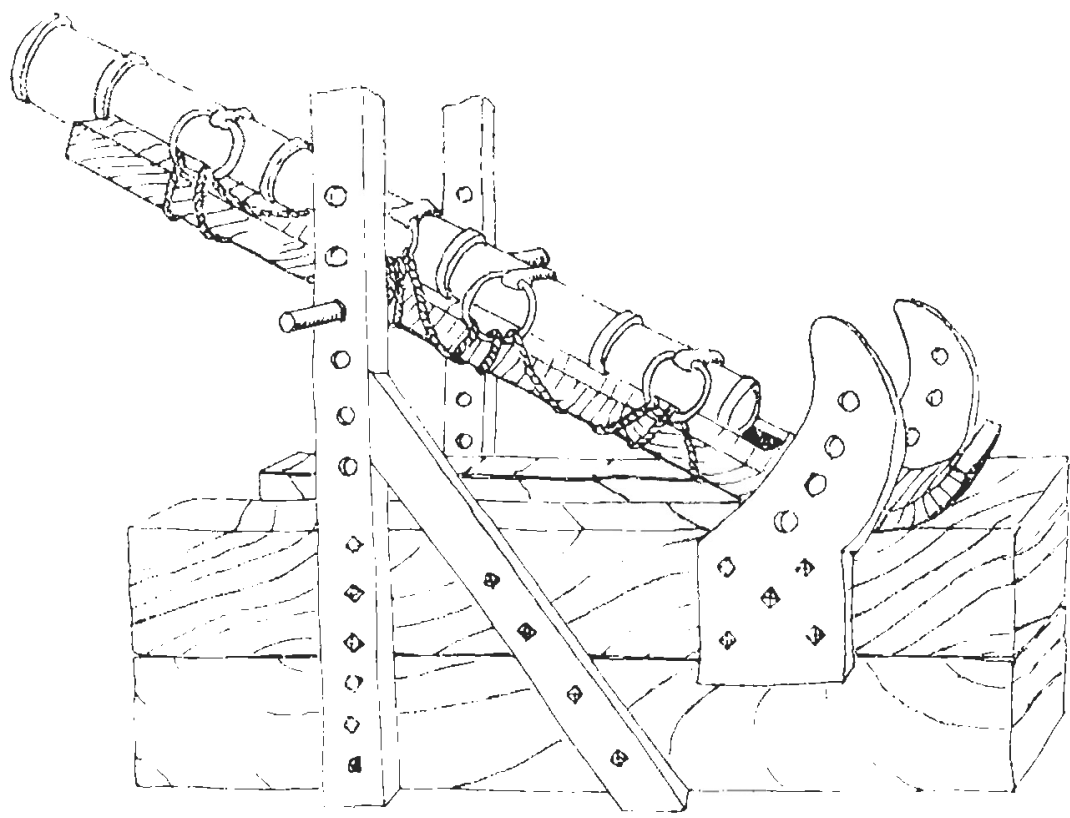

BOMBARDA

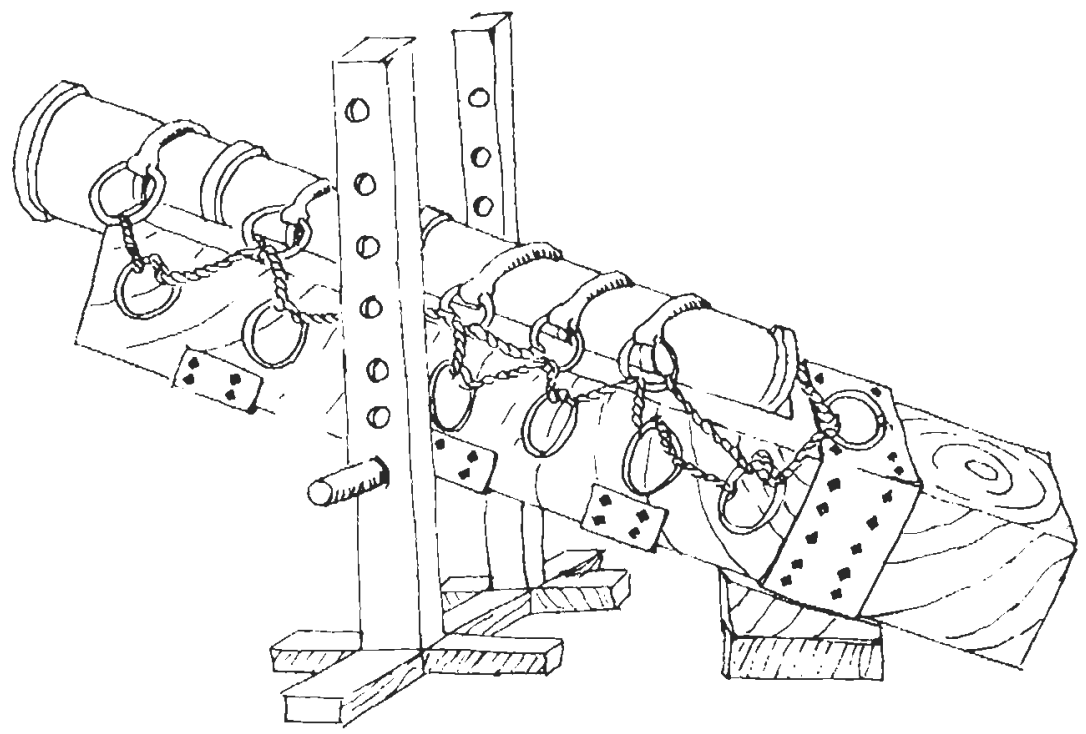

PASAVOLANTE 


\section{Piezas de tiro curvo}
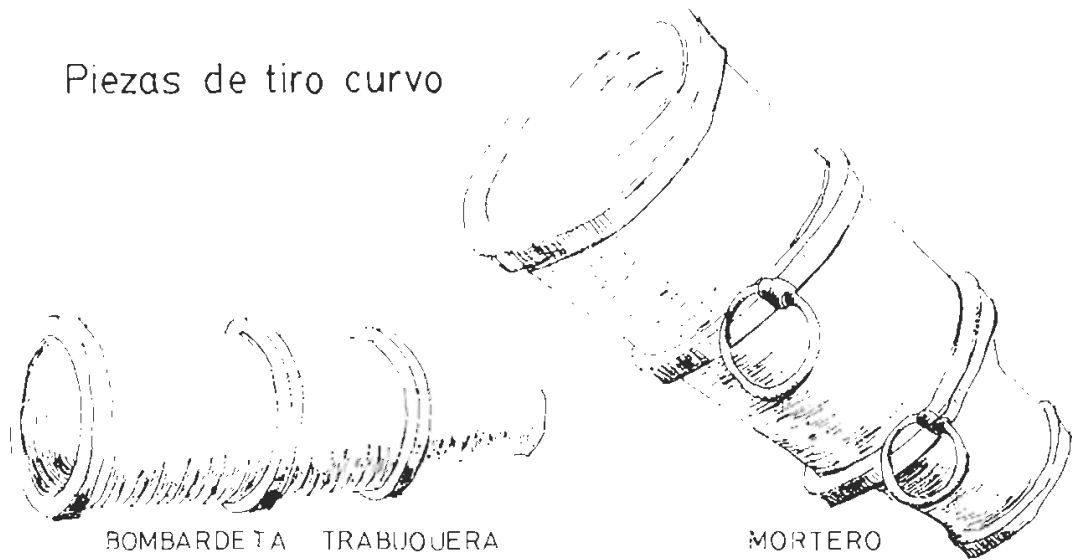

Piezas menudas

FALCONE TE

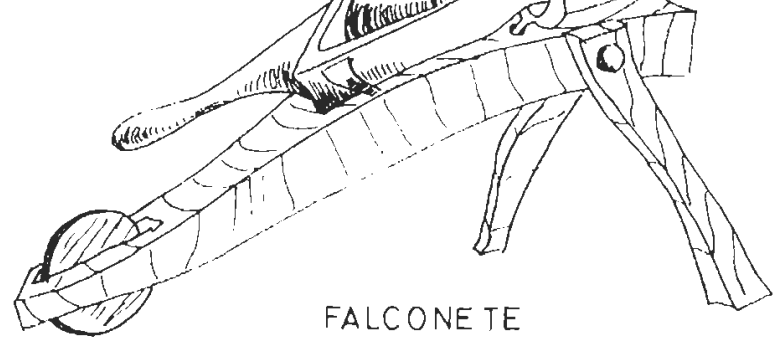

(1) (6) 1414$)$

(mo delo principio siglo XVI) 
bardas o bombardas, pasavolante, bombarda trabuquera, mortero pedrero y otras - se completa con la construcción de baluartes, normalmente flanqueando los accesos. Son construcciones de poca altura, alargados y en gola, frecuentemente sin techar, al objeto de estar dominadas desde los adarves, caso de ser tomados por el asaltante.

Los muros en talud contribuyen a imposibilitar los trabajos de zapa, reforzar las partes bajas de la muralla, más vulnerables, dificultando su destrucción por los impactos del adversario, lo que retrasa la apcrtura de brechas en los muros; asimismo, como también señala Cooper, para permitir el rebote de los proyectiles arrojados desde los adarves y obligar a la mayor inclinación del material de escalada ${ }^{37}$.

Teóricamente, los castillos deberían ofrecer menor silueta para reducir el blanco, lo que parece reñido con la realidad, ya que, en general, aún en el siglo $\mathrm{xv}$, al menos, la mole de su fábrica parece acusar todo lo contrario, y aún más las voluminosas y destacadas torres de homcnaje, que todavía se construyen. En algún caso, como en los castillos de Coca o la Mota, vemos aminorar el problema al comenzarse la edificación en hondonadas o en el fondo del mismo foso, con lo cual desde el extcrior ofrece menor blanco, y, en cambio, desde el arranque del muro las dificultades para el asaltante en posibles escaladas eran las mismas que en los castillos tradicionales.

En realidad, éste es el problema que señalan algunos y que persiste durante el siglo xv: aún el poder de impacto de las armas de fuego no es tan contundente como para reducir la altura del amurallamiento, más ahora que todavía parece persistir el peligro de escaladas; la menor altura sólo se reserva para las barreras o antemuros que, a modo de parapeto, pretendían mermar el impacto en las partes bajas del recinto, o en los baluartes avanzados, que también reducen su silueta; pero, como se ha dicho, su toma por el adversario no parece significar una consecución definitiva, mientras que las cañoneras instaladas en estos puntos adelantados obligarían a retrasar y distanciar el armamento atacante, dificultando la precisión en el tiro. Será desde el siglo xvi cuando, ante el poder de las armas de bronce de una sola pieza, superando definitivamente a las de hierro forjado y de varias partes, surgidas en los siglos XIV y xv, se impongan definitivamente estos $y$ otros medios defensivos que ahora se esbozan.

Habría que citar, al menos, el desarrollo de la arquitectura militar urbana a finales del siglo $\mathrm{xv}$, de la que es un destacado exponente esta ciudad de Cáceres, donde el potencial agresor de las más importantes fámilias obliga a construir sus palacios como si de verdaderas fortalezas se

${ }^{3 y}$ Cfr. ibíd, págs. 58-60. 
Gladius, Vol. especial (1988), pp. 113-152

tratase, como denotan las torres, con matacanes en las esquinas, o las puertas, protegidas también por matacanes, a veces semicilíndricos, a imitación de garitas, sin que falten en ellos las saeteras y troneras, y que obliga a los Reyes Católicos, por cédula dada en Madrigal en 1476, a disponer y ordenar la demolición inmediata de todas las torres hasta quedar a igual altura que el resto de las casas, prohibiendo la construcción de similares defensas torreadas y de aspilleras y troneras en las de nueva construcción, como se dice: «... por cabsas de algunas torres que están en algunas cassas principales de dicha villa, se ban fecho o ban acaecido grandes escándalos, e movimientos, e ruidos, e feridas, e muertes de omes...» ${ }^{40}$ (Láminas I y II).

\section{LA TŔCTICA}

Los castillos y fortalezas que hemos visto hasta aquí, en su mayor parte, estaban dotados de suficientes recursos para repeler cualquier agresión, aun en el siglo $\mathrm{xv}$, a pesar del concurso, entonces, de la artillería; los medios ofensivos podían ser usados por sitiadores y sitiados. A los más modernos sistemas de ataque se oponían nuevos medios de defensa, a los que se unían las innovaciones arquitectónicas ya citadas y las remodelaciones de las fortalezas, tanto para alojar las nueves piezas de artillería como para salvaguardarse de su efecto.

Tomar un castillo significaba, en la mayoría de las ocasiones, aventajar a sus ocupantes en cantidades de armamento, víveres, pertrechos y personal movilizado, en cuyo caso, en efecto, podía ser tomado o asaltado tras una acción más o menos prolongada - hasta varios meses-; de otra manera, difícilmente podría lograrse, o, en todo caso, con sitios y aislamientos aún más duraderos.

En esta exposición recogemos algunos eventos tomados de las Crónicas castellanas de su tiempo ${ }^{41}$ que pueden ilustrarnos sobre el ambiente bélico que rodeaba las acciones militares frente a estas fortalezas y los recursos materiales y tácticos con los que había que hacerles frente ${ }^{42}$.

to Antonio Floriano Cumbreño, La villa de Cáceres y la Reina Calólica, tomo I, Cáceres, 1917. Cfr. Antonio Navareño Mateos, El castillo de las Arguijuelas..., op. cit.

"Crónica de los reves de Castilla. Desde Allonso X, el Sabio, basta los Católicos don Fernando y doña Isabel, ordenado por don Cayetano Rosell, tomos I, II y III, Biblioteca de Autores Españoles, Madrid, 1953; Fernando del Pulgar, Crónica de los Reyes Católicos, ed. de Juan de la Mata Carriazo, Madrid, 1943.

${ }^{42}$ Cfr. Jorge Vigón, El ejército de los Reyes Calólicos, Madrid, 1968, págs. 183189; Historia de la arlillería española, Madrid, 1946. 
Gladius, Vol. especial (1988), pp. 113-152 Actas del I Simposio Nacional

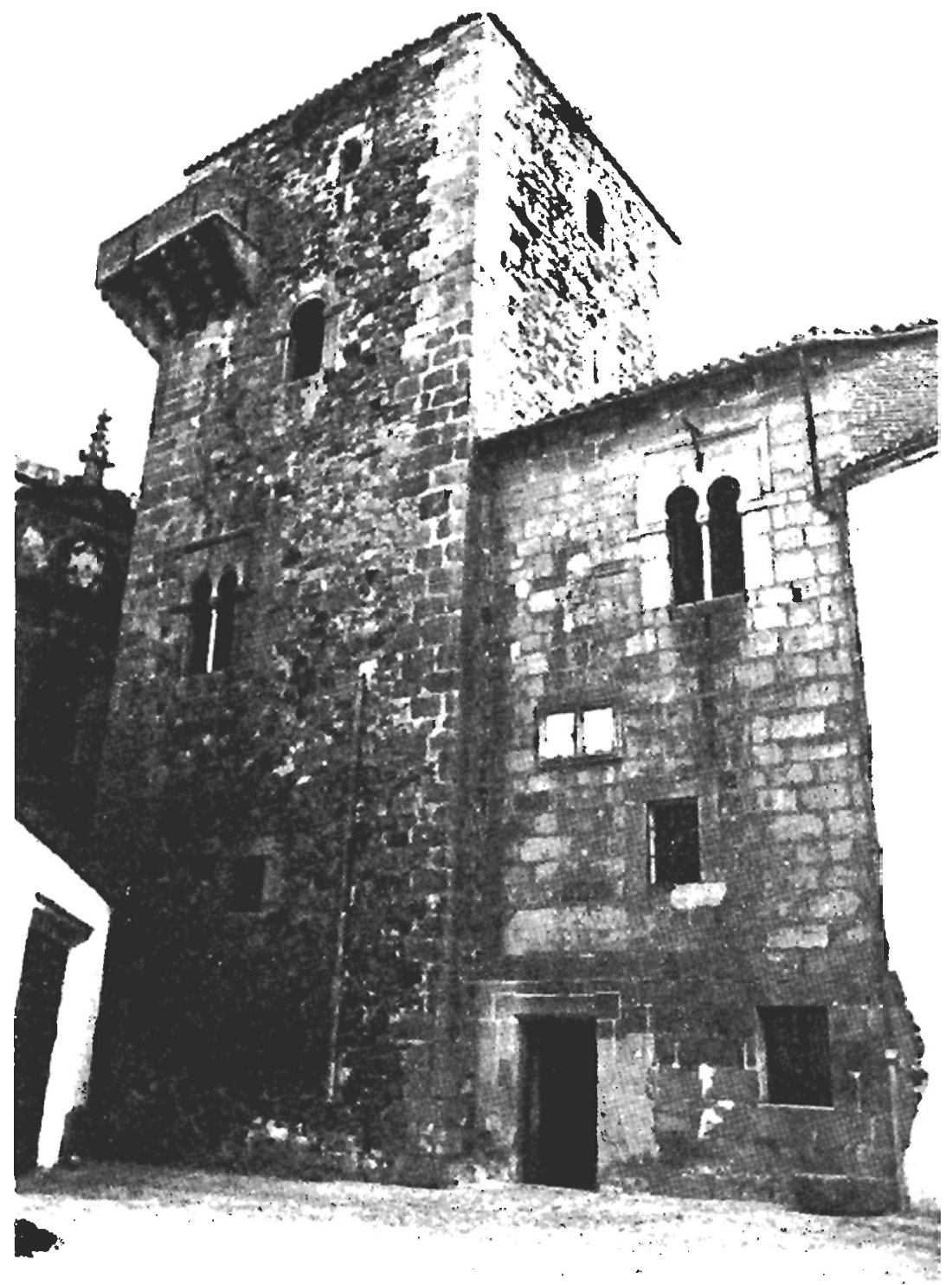

Fig. 17. -Fortificución urbana: Torre de los Plata (Cáacress). 
Gladius, Vol. especial (1988), pp. 113-152 Actas del I Simposio Nacional

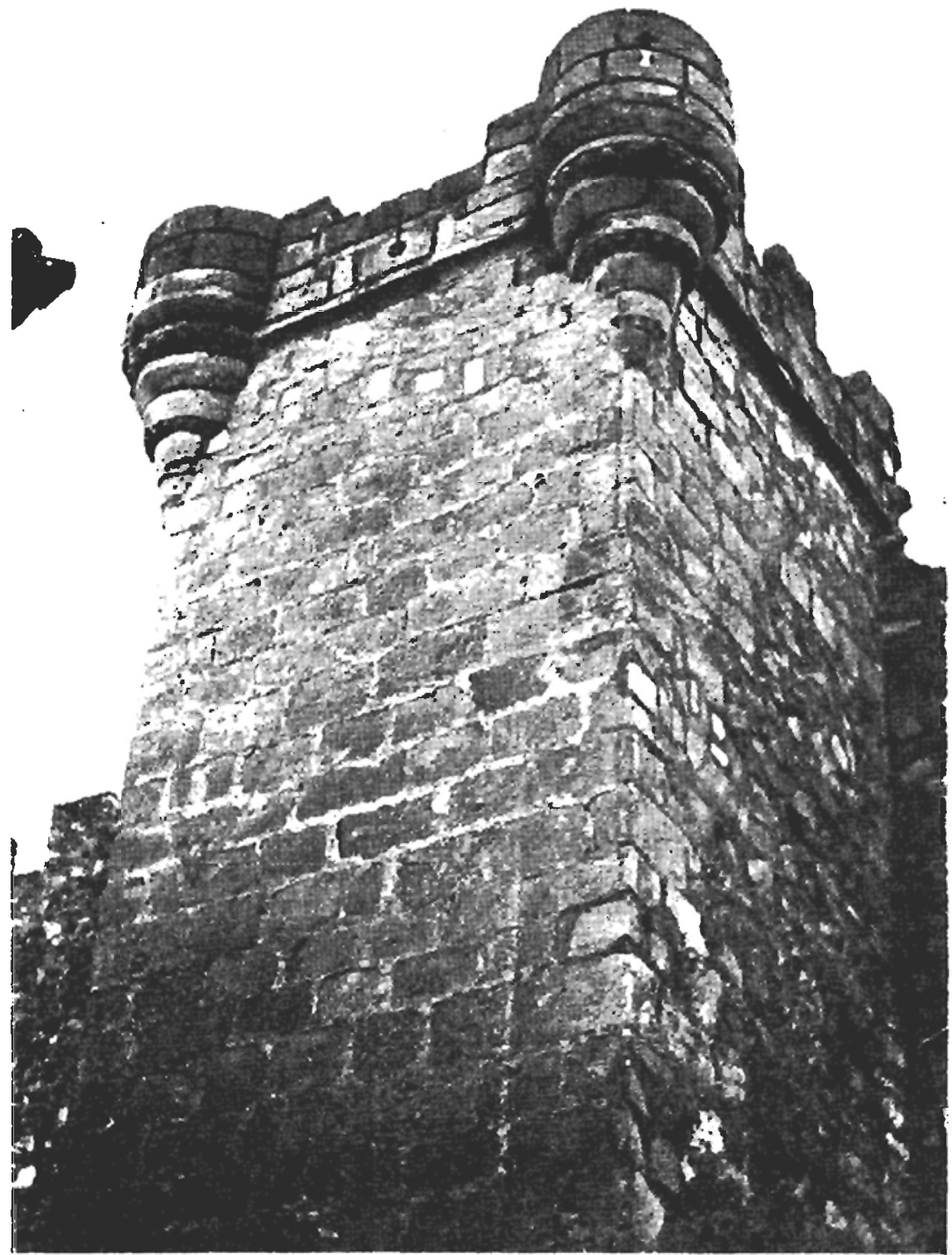

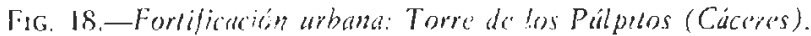


Sitios. Frecuentemente ésta fue la única acción válida para ocupar determinadas fortalezas: sitiándolas durante meses hasta el agotamiento de víveres y provisiones de sus defensores, procedimiento bien antiguo, por cierto, pues, como hemos dicho, hasta mediados del siglo $\mathrm{xv}$ al menos, los elementos defensivos de los castillos, en general, superaron los medios ofensivos aplicados contra ellos; es desde el siglo xvi cuando la artillería denota un considerable avance y aquéllos comienzan a estar desfasados; hasta entonces, en igualdad de fuerzas, prevalecía el castillo, y una de las formas de su conquista era, como hemos dicho, el sitio. Comprendía distintas acciones: el cerco para su aislamiento, acciones de desgaste y castigo, labores de tala en tierras de la comarca, realizadas en parte o en su totalidad, con mayor o menor intensidad, según la importancia de las defensas; todo encaminado a lograr la rendición de la plaza por agotamiento y hambre, frecuentemente después de varios meses de asedio.

Cercar una fortaleza significaba, para sus atacantes, aislarla del exterior, bloqueando posibles ayudas armadas y evitando su aprovisionamiento. Así, Alfonso X cerca y toma Niebla (Huelva), en 1257, tras nueve meses y medio de asedio: «la villa era mucho enfortalecida é bien cercada de buen muro é de buenas torres, labrado todo de piedra, ... estaba bien bastecida de muchas buenas viandas é de muchas buenas gentes ... el Rey por todo esto ovo de morar en aquella cerca muy luengo tiempo, dando gran acucia en los engeños é con muchas peleas que los suyos avian con ellos». Prueba de la necesidad de tiempo y constancia para lograr el fin último es que, tras siete meses de asedio, al ser el real de los cristianos atacado por "grand tempestad de moscas», se acordó partir del cerco, y así se hubiera hecho de no ser aconsejado en sentido contrario: «que en el tiempo que tenian la villa cerca de ganada se querian ir de alli, que lo facian mal, ca los moros bastecella ian e labrarian lo que habian derribado con los engeños de manera que cuando otra vez la quisiesen tomar, que la non podian traer al estado en que entonces la tenian. ... Aben Mafot, rey de Niebla, fué llegando á fincamiento de no tener viandas para si nin para los que con él estavan. E veyendo commo el Rey é los de las hueste porfiaban en aquella cerca, é que se non querian ende partir ménos de tomar aquella villa, acabado nueve meses é medio que aquella villa fue cercada, el rey Aben Mafot envió pedir merced al rey Alfonso que los dejase salir salvos...» ${ }^{43}$. Avanzado el siglo $\mathrm{xv}$, los asedios son más férreos, como se aprecia en el que el rey de Portugal somete a Toro (Zamora) en 1475: «... puso sitio sobre la fortaleza, e mandó poner las estancias lo más junto della que se pudiera, e ansí por de dentro de la çiudad como por de fuera. $Y$ las estançias que pusieron por fuera fueron tan fortifica-

${ }^{43}$ Crónica de los reyes de Castilla, Alfonso X, op. cit., tomo I, cap. VI, pág. 6. 
das, que no pudieron entrar ningund socorro de gente en la fortaleza sin reçebir gran daño; y por esla causa no se pudo socorrer. La qual por no estar bien basteçida, ni de perlrechos ni de basteçimientos, a pocos dias la entregó el alcayde que la tenía al rey de Porlogal... ${ }^{44}$.

Con frecuencia, el asedio acarreaba grandes privaciones a los sitiados y a los sitiadores, como el que el maestre de Santiago somete a Mérida (Badajoz) y su fortaleza, en 1479, durante más de cinco meses: «El Maestre de Santiago... fizo grandes baluartes e cavas, e otras muchas defensas, para que él e sus gentes estoviesen seguros, asy de los que estaban en la villa e en la forlaleza como de olra qualquier gente que viniese de fuera a la socorrer... falleçín los manienimientos a los çercados, e no menos falleçian algunas veces a los cercadores» ${ }^{45}$.

En ocasiones, para precipitar los acontecimientos, se acometían acciones ofensivas y de desgaste a fin de debilitar sus recursos arquitectónicos - torres, puertas - o de subsistencia — pozos, almacenes, caserío-. El cerco de Lerma (Burgos), por Alfonso XI, comprende distintas fases: el aislamiento del recinto por una cerca exterior para proseguir desde allí la acción ofensiva, llegando incluso a tapiar una de las bastidas; en alguna medida se construye una fortificación en derredor de la verdadera fortaleza: "cercar la villa en derredor de muro el de lorres, ... El mandó traer muchos tapiales... el otrosí mandó lapiar las dos bastidas encima de los otros oteros... que el Rey podia dexar alli en aquellas bastidas genles que fecieran gerra á la villa de Lerma» ${ }^{46}$. "El la pelea fué muy brava entre ellos, el muy ferida de lanzas, el de muchas saelas que liraban de una parle el de la olra» ${ }^{47}$. $E l$ porque la villa era asenlada cerca del río de Arlanza, mandó facer puentes, porque por cima dellas podiesen facer la cerca, en manera que la villa fuese cercada lan bien de la parle del rio como de la olra... Et el Rey por eslas cosas mandaba dar grand acucia en aquella labor: el encima de aquella cerca, el de las lorres della fizo facer cadahalsos de madera, c'l bastidas, en que podian estar et morar los omes los guardaban de día el de noche... El desque la villa fue cercada por esia manera, mandó poner engeños, el cabritas, el trabucos tras aquel muro en muchas partes derredor de la villa» ${ }^{4}$. Tras ello, el rey cobró Lerma y mandó derribar los muros y allanar las cavas ${ }^{49}$. Algo simi-

4 F. del Pulgar, op. cil., t. I, pág. 128.

" Ibial., pág. 386.

4o Crónica de los reyes de Castilla, Alfonso XI, op. cit., t. I, cap. CLVIII, páginas $275-276$.

${ }^{47}$ Ibid., cap. CLXI, pág. 277.

4* Ibid, cap. CLXIII, pág. 278.

¿ Ibíd., cap. ClXXII, págs. 282-283. Cfr. Claudio Sánchez Albornoz y AntoNio Viñas, Lecturas históricas españolas, Madrid, 1981, págs. 175-184. 
lar, aunque con más efectivos, realiza el rey Fernando el Católico al cercar la fortaleza de Zamora: "E mandó hacer una gran lapia por alajo, la cual apartó la fortaleza de la çiudad, de manera que por la forlaleza no podia ninguna gente entrar en la ciudad. E por de luera de la çiudad mandó poner onze estançias contra la forlaleza, e cada una de aquellas estançias mandó forneçer de mucha gente bien adereçada de armas y pertrechos e artillería. E otrosí mandó forlificar las cavas... e mandó asimesmo traer yngenios e lombardas para la combatirs ${ }^{\$}$.

La lalas y saqueos realizados en los campos y propiedades de los sitiados contribuían a incrementar los daños ocasionados en los cercos; en algún caso, el anuncio de éstas fue el detonante para la rendición de una plaza, como en Jerez, tras un mes de asedio por Alfonso $X$, en 1255: "... sacó sus buestes é fué á cercar, é lóvola cercada un mes. E los moros de la villa, por desviar que los de la hueste del rey Alfonso non les talasen los olivares ni las huerlas, cuidando fincar en la villa é sus heredades, é que despues de alguin liempo podrian salir de premia é de poder de los cristianos; et otrosi, porque eran despegados del señor que tenian, ante que el rey don Alfonso mandase armar las genles nin les ficiesen daño en las beredades nin en las otras cusas, envióle decir que lovoese por bie: de los dejar en sus casas é con lodas sus heredades, e que les entregarian la villa é le darian de cada año el tribulo que daban a su señor... ${ }^{51}$.

Ante el castillo de Locovín -entre Alcalá y Pliego-, Alfonso XI manda talar los panes, viñas y huertas de los moros y simultáneamente minan una de las torres donde se encontraba el pozo de suministro de agua ${ }^{52}$. Se reiteran estas acciones entre otras cosas; el rey de Granada ordena la tala de viñas, huerıas y olivares como último recurso ante la imposibilidad de tomar Alcaudeie en $1408^{53}$.

Asalios. Obviamente, sólo algunas veces fue preciso recurrir al silio para la rendición de una fortaleza, entre otras razones porque, en ocasiones, los sitiadores no tenían más provisiones, recursos ni tiempo que los sitiados; consiguientemente, la acción había de realizarse por la fuerza, con distintas modalidades, según los recursos propios y los del adversario, assí a escala vista o acción directa frontal, por sorpresa o por brecha abier. ta en los muros ${ }^{j 4}$; el primero de los sistemas, incluso el segundo, prácticamente imposibles desde mediados del siglo xv.

* F. del Pulgar, op. cil., pág. 173.

"Crínica de los reyes de Castilla, Aljonso X, op. cit., t. I, cap. IV, pág. 5.

"Crónica de los reyes de Castilla, Alfonso XI, op. cit., I. I, cap. CCLVII, píginas 332-333; cfr. nota 66 .

"Crónica de los reyes de Castilla, Juan II, op. cil., 6. II, cap. IV, pág. 305.

¿ JorGF. VIGón, El ejércilo..., op. cit., págs. 184-186. 
A escala vista, las ocasiones se localizan en fortalezas de menor consideración, con reducido potencial defensivo; en todo caso, se solía simultanear con una acción de entretenimiento o distracción. Así, en la entrada de los musulmanes en el castillo de Jerez, en tiempo de Alfonso X, entonces en poder de los cristianos ${ }^{55}$, se lucha cuerpo a cuerpo en distintas dependencias y torres.

Acometida propia de esta modalidad nos parece la del mariscal Pedro García Herrera y otros caballeros con sólido ejército, en 1407, ante la ciudad de Vera (Almería), en manos de los musulmanes, si bien no se llegó a explotar el éxito por insuficiencia de pertrechos: «E los Christianos que se hallaron en esta entrada fucron ocbenta bombres darmas, é quinientos de caballo á la gineta, é tre mil peones lanceros é vallesteros...»; tras combatir la ciudad por tres puertas, no pudieron tomarla por no haber llevado escalas: «E por eso es gran error quando gente poderosa entra, no llevar mantas y escalas y los pertrechos necesarios para combatir; porque muchas veces se halla disposición para poderse ganar algunos lugares, é piérdense por no tener pertrecbos los que para ello convienen...» ${ }^{\text {xi. }}$.

$\Lambda$ un con el concurso de artillcría, parecc que la acción quc pretende el rey de Granada en 1408 frente a Alcaudete (Jaén), en poder de Juan II, puede encuadrarse en esta modalidad: con 7.000 de caballo, 120.000 peones, «é traía consigo lombardas y escalas y mantas y otros mucbos pertrechos»; hizo tres cuadrillas de peones de hasta 40.000 cada una, y con cada una, 500 caballos. Se alternaban en el asalto una y otra. Mientras tanto, «tiraban los moros a la villa con quatro lombardas, e muchos truenos». Puso ocho escalas en la villa y muchas mantas en derredor ${ }^{57}$.

La toma de una fortaleza por sorpresa era procedimiento económico y rápido, pero quizá sólo aplicable ante fortalezas poco importantes y de escasa guarnición. Como señala Clausewitz, la sorpresa es el medio para lograr la superioridad numérica en un punto determinado, al que se añade el efecto moral que ésta produce en los cercados ${ }^{58}$. En 1325 , tras la toma de Olvera por Alfonso XI, cercó el castillo de Pruna, situado en una cima roquera; mientras se ataca por la parte donde se encuentra el pueblo, un pequeño número de asaltantes escala la roca por el lugar más difícil y, por tanto, menos protegido, continuando otros el ascenso por escalas de soga que aquéllos habían colocado ${ }^{59}$.

También por sorpresa se escala la torre llamada del Tesoro en Va-

"Crónica de los reyes de Castilla, Alfonso X, op. cit., t. I, cap. X, págs. 8-9.

${ }^{5}$ Crónica de los reyes de Castilla, Juan II, op. cit., t. II, cap. V, pág. 279.

${ }^{5}$ Ihid., cap. IV, pág. 305.

5 Carl von Clausewitz, De la guerra, Barcelona, 1976, pág. 234.

5.) Crónica de los reyes de Castilla, Alfonso XI, op. cit., t. I, cap. LVIII, pág. 208. 
lencia (de Alcántara) en tiempo de Alfonso XI, tomando el castillo, entonces en poder del Rey de Portugal ${ }^{\circ}$.

En el cerco de Carmona por Enrique II, en 1371, hizo escalar una torre, de noche, donde subieron cuarenta hombres de armas ${ }^{61}$.

Abrir brecha en el muro, sin duda, significa el procedimiento obligado en la mayoría de las ocasiones y el más costoso en hombres y material, pero parece sería imprescindible ante la disposición y medios defensivos de la mayoría de las fortalezas. Este, a su vez, podrá lograrse en base a distintas modalidades: socavando el muro al pie del mismo o con piezas de tiro mecánico y de fuego más tarde, a distancia; labor de zapa o con ingenios, respectivamente. Cada procedimiento contaba con sus elementos de seguridad, y el adversario, con los consiguientes de defensa ante su acción, como luego veremos.

Trabajos de zapa o ininas. El objetivo es hacer una perforación en el muro por donde poder penetrar en el interior de la fortaleza. En csta modalidad, la perforación se realizaba manualmente al pie de la misma muralla; para ello había que acercarse al muro con distintos elementos protectores, al aire libre con paveses y mantas, o a través de cavas encubiertas o por vía subterránea, haciendo túneles y minas bajo tierra hasta topar con el mismo muro; en cualquier caso, una vcz en contacto con éste, sc trataba de socavar sus cimientos y perforarlo para con ello producir el desplome del mismo; el procedimiento tradicional para lograrlo era poner. el muro en cuentos - apeado sobre maderos-, tras lo cual se quemaba esta madera y con su destrucción acaecía la del muro que soportaba; más tarde, el procedimiento, mucho más rápido, era la explosión directa con pólvora.

Simultáneamente a esta labor, sus realizadores contaban con la scguridad que les proporcionaban diversos medios defensivos, que les ponían a cubierto del tiro adversario; así, la seguridad del túnel o la que les proporcionaban las mantas y bancos pinjados — piezas de cobertura bajo las que se guarnecían- cuando los trabajos se realizaban al aire libre.

Obviamente, los sitiados tenían igualmente distintos procedimientos para evadirse de estas acciones: disponían de buenas aspilleras, alınenas, matacanes y corachas donde estar a cubierto y efectuar un tiro muy preciso o arrojar materiales combustibles sobre los bancos pinjados e incendiarlos, arrojándoles umanojos de lino o de cáñamo bañado en aceite o pez ardiendo, con los cuales quebraban algunos bancos pinjados e mantas» ${ }^{2}$. Con frecuencia se efectuaban contraminas. En 1408, en tiempos

(2) Ibíd, cap. CCV, págs. 304-305.

${ }^{n}$ Crónica de los reyes de Castilla, Enrique II, op. cit., t. II, cap. I, pág. 8.

h. Jorge, Vigón, El ejércilo..., op. cit., pág. 185, citando a Pulgar. 
de Juan II, el rey de Granada cerca Alcaudete, en poder de los cristianos; éstos "contraminaron por dentro de la villa, é loparon con la mina de los Moros, y entraron por las minas, é malaron á los que las bacia, é lomaronle's lodas las berromientas con que labraban» ${ }^{63}$. A veces se organizaban verdaderos entrentamientos bajo tierra: «de manera que muchos días acaeció pelear por dos parles debaxo de tierra, e por ençima de tierra por tres o por cualro» en el cerco del castillo de Burgos, en $1475^{6}$. No pocas veces se dedicaban los sitiados a destruir durante la noche los trabajos realizados por los sitiadores.

Seleccionamos algunos casos que nos informan de distintas situaciones creadas en este sentido: en el cerco de Cástro del Río (Córdoba) por el rey de Granada, los cristianos de Alfonso XI tapaban durante la noche los portillos abiertos por las huestes musulmanas: "gente de pie lanceros, et fonderos, que traían muchos picos el muchos azadones, el veno al logar del castro, casilllo de Cordoba» ${ }^{65}$.

En el cerco de Alcalá (La Real) por Alfonso XI parece más efectivo el trabajo de minas que el de percusión de los ingenios para derribar una torre: "el por esto el Rey mandó que le ficiesen cuevas desde alexos, que fuesen so la lierra, fasla que llegasen al logar dó podiesen aquella lorre poner subre cuentos, porque cayese, el les tirase el agua de aquel pozos "s.".

En 1362, en la toma de Calatayud (Zaragoza) por Pedro I, los castellanos tenían más de cuarenta brazas de los muros en cuentos, de manera que veían por debajo de éstos a los que andaban por la villa ${ }^{67}$.

En este género de operaciones se aliaba con los sitiados el mal tiempo: en caso de lluvias, el trabajo de zapa podía resultar considerablemente efímero y peligroso a causa de los derrumbamientos, como en el cerco de Ciudad Rodrigo (Salamanca) por Enrique II, en 1370, donde además, para su mala fortuna, una de las minas abiertas vino a dar en un lienzo del muro ciego por su interior ${ }^{t 3}$.

Con ingenios mecánicos y artillería. Indudablemente, el sistema frontal para abrir brechas en los muros era mediante el empleo de armamento pesado de tiro y la percusión de proyectiles pétreos o de metal, cuya acción, desde luego, no parece demasiado contundente en este tiempo. Tras abrir brecha, se salvaba el muro con escalas o se deslizaban al interior desde las bastidas. Desde el siglo xIV comienza el uso de las armas

Crónica de los reyes de Castilla, Juan II, op. cit., t. II, cap. IV, pág. 305.

is F. vel Pulgar, op. cil., t. I, pág. 105.

"Crónica do los reyes de Castilla, Aljonso XI, op. cit., t. 1, cap. CVIII, páginas $242-243$

Ibid., cap. CCLVIl, págs. 332-333.

"Crónica de los reyes de Castilla, Pedro I, op. cit., t. I, cap. XII, págs. 523-524.

"Crónica de los reyes de Castilla, Enrique II, op. cit., $t$. II, cap. 1 , pág. 5. 
de fuego, rudimentarias entonces, por lo que se simultanean éstas y las tradicionales hasta el $\mathrm{xv}$, a finales de cuyo período ya quedan marginados los antiguos ingenios mecánicos. Esta revolución ofensiva hace necesarias determinadas reformas en los castillos y fortalezas de orden arquitectónico y táctico, además de la lógica inclusión de las mismas armas entre sus pertrechos.

Las piezas que llaman «engeños» comprenden diversos tipos de máquinas: grúas, bastidas, torres de madera, escalas, tiros de impulsión mecánica, como cabritas, trabucos y otros, entre las of ensivas, y las ya citadas gatas, bancos pinjados, mantas (para cubrir hombres y material), estancias (debían ser construcciones de seguridad y de alojamiento), entre las defensivas "9.

En un principio resulta difícil diferenciar las armas de fuego y las convencionales más primitivas. En nuestro caso, como veremos, nos parece ver mencionadas las de fuego desde el siglo XIV: «truenos» y «trabucos» en el cerco de Algeciras, en 1342-1343; en el siglo XV se mencionan claramente piezas propiamente artilleras, especialmente «lombardas».

Citaremos algunas acciones claramente destructivas que nos manifiestan con nitidez el efecto devastador y moral que producen.

En el cerco de Tarifa (Cádiz) por los musulmanes, mientras ellos se preocupan de destruir con sus ingenios las torres de la fortaleza: «...e otrosí tirando con los engeños de día á la cérca et á las torres de la villa; et de nocbe liraban á la villa, porque lós omes non podiesen dormir seguros ${ }^{70}$, los cristianos se ocupaban en realizar cavas para evitar el avance de las máquinas de los sitiadores: "ca ellos tenian la cava bien fonda, et bien limpia, porque de cada noche la afondaban; et otrosí cada nocbe tornaban á la villa las piedras que lanzaban de dia fuera contra los mo$\operatorname{ros} \ldots{ }^{71}$.

La aparición de la artillería no trae consigo la disminución de los ingenios tradicionales; al menos en un principio, su uso se simultanca, si bien las acciones militares se complican en la medida que ésta progresa y se hace más contundente (Figs. 19-23).

En el cerco de Algeciras (Cádiz), en 1342-1343, mantenido por Alfonso $\mathrm{XI}$, los moros sitiados usan «truenos», que parecen el preliminar de las armas de fuego, y simultáneamente entran en acción las balkestas: "El los moros de la ciudad lanzaban mucbos truenos contra la bueste, en que lanzaban pellas de fierro muy grandes... et otrosi lanzaban con los truenos saetas muy grandes et muy gruesas... tiraban a los christianos

${ }^{14}$ Cfr. Jorge Vigón, El cjércilo..., op. cit., págs. 224 y sigs.

ii) Crónica de los reyes de Castilla, Allonso X1, op. cit., t. I, cap. CCXLI, pág. 317.

"Ibid., cap. CCXLV, págs. 320-321. 
muchas saeladas de arcos el de ballestas" "2. Los cristianos empleaban ingenios tradicionales, al parecer fácilmente abatibles por los sitiados, y dos trabucos, que nos parece identificar como primitiva arma de fuego, que más tarde dará lugar a una auténtica pieza de artillería, la lombarda trabuquera o mortero, pieza de tiro curvo, utilizada con idéntica función con anterioridad: «(El Rey)... mandó facer mas de veinte engeños. Et los de la ciubdat liraron primeramiente son sus engeños, et lanzaban lan cierlos que asi como alzaban los cbristianos las cureñas del engeño, luego ge las quebraban. Et por esio el Rey mandó poner en el Jonsario dos trabucos de los que avian lecbo en Sevilla los Gioneses...» ${ }^{73}$. El ponerlos en fosos nos confirma su tiro curvo y al mismo tiempo nos informa de uno de los medios de protección.

Cuando los cercados disponían de sólido armamento y de suficientes defensas arquitectónicas, la tarea agresora se hacía extraordinariamente difícil; así vemos cómo ello impide el uso de armamento de tiro horizontal, en cuyo caso había de ser protegido por cercas, muros, mantas, etcétera, evitando la descubierta, garantizando tan sólo el disparo de armas de tiro curvo como los trabucos o más tarde los morteros, que, lejos de un tiro rasante, podían permitir ser prácticamente enterrados o situados en fosos, como vemos, fuera del ángulo de tiro de los sitiados.

De este cerco de Algeciras podemos extraer algunas consideraciones respecto a la organización de ataques y defensas de fortalezas en el alboreo del uso de las armas de fuego; la defensa del material de los sitiadores se hacía mediante «bastidas» para la seguridad del armamento: "pensó de lacer una bastida de madera alta en guisa de lorre, en que e'stoviesen los que guardasen los trabucos del fonsario...» ${ }^{74}$ "... e ficieron labrar dos bastidas de madera á figuras de torres, et levaronlas sobre ruedas... quisieronlas labrar de dentro de adoves » ${ }^{75}$. Por otra parte, se hacían cavas - trincheras - para el movimiento del personal donde se guarnecía el material, armamento y tropa, se extraía la piedra para los ingenios, construyendo simultánemente cercas, casi amuralladas; "mandó facer una cava muy fonda et muy grande... et fizo poner toneles por encima de la cava llenos de lierra el piedra, et facian dellos grand antipecho» ""; "... mandó facer el Rey muchos adoves de barro: et pusieron

i2 Ibid., cap. CCLXX. pág. 344.

7 Ibid., cap. CCLXXVII, pág. 351.

is Jbid, cap. CCLXXIX, págs. 351-352.

7 Ibíd, cap. CCLXXXV, pág. 357. Cir. «Castillo de madera», en Claudio SínChez. Albornoz y Antonio Viñs, op. cil., págs. 133-136.

"Crómica de los reyes de Castilla, Allonso XI, op. cit., t. I, cap. CCLXXXV, pág. 356. 
luego manlas de madera en el canto de la cava» ${ }^{77}$. Construyendo a veces esiancias o alojamientos y baluarles para protegerse del exterior. En el cerco del castillo de Burgos, en poder de Juan de Stúñiga (partidario del rey de Portugal), por Fernando el Católico en $1475^{73}$ : «Mandó asimismo facer grandes cavas en circuylo de loda la fortaleza, de manera que ninguno podia salir ni entrar en ella. E las eslanças que eslauan por de luera de la cibdad fueron muy forlificadas de cavas e baluartes; porque si el rey de Portugal la viniese a socorrer, no podiese gente ninguna entrar en la forlalcza sin reşebir daño grande. Mandó asimismo poner muchas lombardas, e otros tiros de pólvora...» El procedimiento de defensa ante este tipo de acciones pretendía la destrucción del armamento contrario con el uso del tiro de ingenios o mediante el contacto directo y frontal saliendo de la fortaleza, en especial durante la noche.

La bastida, a modo de torre móvil, venía a ser la homóloga, a menor escala, de las sólidas tortes de fábrica en los grandes recintos fortificados; en ocasiones, se pretende emular éstas reforzándolas con adobe, como hemos visto; en cualquicr caso, desde el siglo xv la operatividad de estas torres se reduce, pueden ser fácilmente abatidas por la artillería y por ello han de ser montadas a mayor distancia y posteriormente desplazadas por un trayecto previamente allanado ${ }^{79}$, en cuyo caso el adversario se defiende de su avance haciendo cavas o fosos, lo que acarrea nuevos trabajos para el agresor, o incendiando bastidas y mantas con fuego de alquitrán y estopa, como se pone de manifiesto en el cerco que Juan II somete a Antequera (Málaga) en 1410 , entre otros ${ }^{20}$. Se simultanea así un conjunto de acciones complejas, desde los tiros de la artillería hasta los enfrentamientos cuerpo a cuerpo, haciendo o deshaciendo cavas, poniendo o quemando mantas, construyendo o destruyendo ingenios, según se tratase de sitiadores o sitiados. Desde el siglo xv, las operaciones que genera el traslado del material pesado que se utilizaba entonces pone de manifiesto la envergadura de estas acciones: es un auténtico ejército de operarios especializados y de las más diversas profesiones. El tren de artillería que se describe cuando el infante Juan II entra en la villa de Zahara (Cádiz) en 1407, aunque resumidamente, su enumeración global viene a ser un inventario del armamento y material usado en asedios a principios de este siglo: cinco lombardas sobre carretas, con guarnición de unos ciento cincuenta hombres; diez mantas con sus pertrechos y madera, con ciento cincuenta hombres; pertrechos de minas y alquitrán, con cien hombres; la pólvora, con ochenta hombres más cinco carretas vacías de retén; los pa-

"Ibid., cap. CCLXXXIX, pág. 359.

"F, DEL Pulgar, op. cit., t, I, pág. 151.

"Crónica de los reyes de Casillla, luan II, op. cit., t. II, cap. XI, págs. 320-321.

Ihid., caps. XIII y sigs., págs. 321-329. 
veses, con ciento cincuenta hombres; las arcas de los pasadores, con ochenta hombres; fraguas de herrero, con ochenta hombres; cincuenta quintales de hierro, con cincuenta hombres; herramientas - picos, azadas, palas, chapa, etc.--, con ciento cincuenta hombres; pertrechos de tornero y otros, con cincuenta hombres; un ingenio grande, con doscientos hombres; dieciséis truenos, con cincuenta hombres; piedras de munición para lombardas y truenos, con ciento cincuenta hombres; así como carboneros, carpinteros, pedreros, carreteros, sogueros, taladores, etc.; organizado en secciones al frente de cada una de las cuales se dispone un caballero ${ }^{81}$.

Parece que este contingente se asentó ante Setenil (Cádiz); tres lombardas dispararían sobre la muralla del alcázar, donde estaba la puerta, y dos lombardas de fuslera al otro lado de la villa ${ }^{82}$.

La frecuencia de tiro de estas armas no es bien conocida; la sucesión de sus disparos no parece que fuera muy intensa. Por nuestra parte, contemplando la descripción de este asedio sobre el castillo de Setenil, observamos que al acabarse la munición el infante ordena que cada día cinco caballeros y ricos-hombres trajeran en sus carretas ocho piedras cada uno, cuarenta piedras en total, lo que nos apercibe, primero, que las piedras o bolaños debían ser considerablemente pesadas y abultadas (como máximo ocho en una carreta) y que la frecuencia de tiro no debía ser mayor de diez piedras por día para cada lombarda, pues sólo son cuatro las que parecen en servicio, una de ellas se quebró, a pesar de que, según se dice, se disparaba día y noche y al parecer con efectos contundentes al indicar que se hacía gran daño a los adarves, especialmente con las lombardas de fuslera ${ }^{83}$.

La defensa de la fortaleza, ante el efecto ya acusado de estas armas de artillería, se centra en el reforzamiento de muros; en este caso, los musulmanes hacen un muro muy grueso de piedra seca acaparando algo el muro de la torre mayor ${ }^{* 4}$. En la alcazaba de Málaga se hace otro tanto, envolviendo sus muros con otros de argamasa y de mampostería ${ }^{35}$. Fuenterrabía (Guipúzcoa), tras dos meses de asedio en 1476 por los franceses, y aun utilizando lombardas gruesas, no pudo ser tomada, según se dice: «Por las grandes defensas que la villa tenía por defuera, e por la gran gente de dentro que la delendias ${ }^{86}$.

Vemos, pues, cómo hasta el siglo $\mathrm{xv}$, aun con el avance que supone el desarrollo de la artillería, el castillo, en general, supera en capacidad de

"I Ibid., cap. XXXVII, págs. 292-293.

"I hid, cap. XLI, págs. 294-295.

:I Ifid., cap. XLIII, pág. 295.

is Ihid.

* Leopoldo Torres Balbís, Ars Hispaniac, IV, op. cit, pág. 161.

* F. del Pulgar, op. cil., págs. 180-186. 
defensa a los medios ofensivos utilizados hasta entonces, porque la misma artillería fue utilizada para la seguridad de éstos y porque las reformas e innovaciones que se obraron en su arquitectura parecen suficientes para contrarrestar el efecto de las armas de fuego contemporáneas.

Será a partir del siglo xvi cuando los castillos hasta ahora construidos comienzan a verse desfasados y superados por los modernos y perfeccionados medios utilizados desde entonces, reduciéndose a una función doméstico-residencial; se da paso a una nueva concepción de la arquitectura de fortificaciones, que ahora tiene que hacer frente a unos recursos materiales y tácticos notablemente evolucionados. 